\title{
Differences in the stemness characteristics and molecular markers of distinct human oral tissue neural crest-derived multilineage cells
}

\section{Shigehiro Abe ( $\square$ abe.shigehiro@nihon-u.ac.jp )}

Nihon University School of Medicine Graduate School of Medicine: Nihon Daigaku Igakubu Daigakuin Igaku Kenkyuka https://orcid.org/0000-0003-1413-5654

\section{Atsushi Kaida}

Tokyo Medical and Dental University: Tokyo Ika Shika Daigaku

\section{Keiichiro Nakazato}

Tokyo Medical and Dental University: Tokyo Ika Shika Daigaku

\section{Naoko Yokomizo}

Tokyo Metropolitan Hiroo Hospital: Tokyo Toritsu Hiroo Byoin

\section{Yutaka Kobayashi}

Tokyo Metropolitan Hiroo Hospital: Tokyo Toritsu Hiroo Byoin

\section{Masahiko Miura}

Tokyo Medical and Dental University: Tokyo Ika Shika Daigaku

\section{Toshio Miki}

Nihon University School of Medicine Graduate School of Medicine: Nihon Daigaku Igakubu Daigakuin Igaku Kenkyuka

\section{Chiaki Hidai}

Nihon University School of Medicine Graduate School of Medicine: Nihon Daigaku Igakubu Daigakuin Igaku Kenkyuka

\section{Hisataka Kitano}

Nihon University School of Medicine Graduate School of Medicine: Nihon Daigaku Igakubu Daigakuin Igaku Kenkyuka

\section{Tetsuya Yoda}

Tokyo Medical and Dental University: Tokyo Ika Shika Daigaku

\section{Research}

Keywords: multilineage cells, apical papilla, periodontal ligament, oral mucosa, neural crest-derived stem cells, cell differentiation

Posted Date: September 8th, 2021

DOI: https://doi.org/10.21203/rs.3.rs-877326/v1 
License: () (1) This work is licensed under a Creative Commons Attribution 4.0 International License. Read Full License

Version of Record: A version of this preprint was published at Cell Proliferation on June 18th, 2022. See the published version at https://doi.org/10.1111/cpr.13286. 


\section{Abstract \\ Background}

Although multilineage cells derived from oral tissue, especially the dental pulp, apical papilla, periodontal ligament, and oral mucosa, have neural crest-derived stem cell (NCSC)-like properties, the differences in the characteristics of these progenitor cell compartments remain unknown. The primary aim of the current study was to elucidate these differences.

\section{Methods}

Multilineage sphere-forming apical papilla-derived cells (APDCs), periodontal ligament-derived cells (PDLDCs), and oral mucosa stroma-derived cells (OMSDCs) from the same individuals were isolated from impacted developing teeth. All sphere-forming cells were characterized by biological analyses of stem cells. Additionally, composites of these cells and multiporous hydroxyapatite scaffolds were transplanted into immunocompromised mice.

\section{Results}

All sphere-forming cells expressed neural crest-related markers. Although APDCs and PDLDCs showed greater mineralized-cell differentiation, they exhibited poorer differentiation into adipocytes in vitro than OMSDCs. In immunocompromised mice, APDCs were better able to form hard tissues than PDLDCs and OMSDCs. Moreover, the expression of certain tissue-specific markers, such as CD24 and CD56 (NCAM1), differed among the tissue-derived cells. Surprisingly, the expression of only CD24 and CD56 could be discriminated among human tissues.

\section{Conclusions}

Our results suggest that although cells having NCSC-like properties present the same phenotype, they differ in the expression of certain markers and differentiation abilities. The present study is the first to demonstrate the differences in differentiation ability and molecular markers among multilineage human APDCs, PDLDCs, and OMSDCs obtained from the same patients and, concomitantly, the same sites and identify these tissuespecific markers in the human tooth developmental process.

\section{Background}

Oral and maxillofacial tissues are attractive cell sources for regenerative medicine. A sufficient number of stem cells can be obtained from the third molar tissue without causing aesthetic issues or the collection of surplus tissue. Dental pulp stem cells (DPSCs), ${ }^{1-6}$ periodontal ligament stem cells (PDLSCs), ${ }^{7}$ and oral mucosa stromal stem cells (OMSCs) $)^{8,9}$ are derived from the neural crest (NC) ${ }^{10,11}$ Chai et al. confirmed that cranial NC cells contribute to the formation of condensed dental mesenchyme, dental papilla, odontoblasts, 
dentin matrix, dental pulp, cementum, and periodontal ligament using Wnt1-Cre-R26R transgenic mice. ${ }^{10}$ Furthermore, Xu et al. suggested that $90 \%$ of colony-forming mouse oral mucosal cells are NC-derived and that OMSCs contain cells from the NC. ${ }^{11}$ However, these experimental procedures cannot be used for human samples. Moreover, neural crest-derived stem cell (NCSC)-like cells have been isolated from various mice and human tissues, including the skin, ${ }^{12-14}$ heart, ${ }^{15}$ bone marrow, ${ }^{16}$ dental pulp, ${ }^{17-20}$ periodontal ligament, ${ }^{21,22}$ and oral mucosa, ${ }^{23,24}$ using the sphere formation technique, which can enrich stem/progenitor cells. ${ }^{12-24}$ NCSCs express NC-related markers and can differentiate into cells of mesenchymal lineage, including osteoblasts, chondrocytes, adipocytes, and smooth muscle cells, as well as cells of neural lineage. ${ }^{25}$ Studies have shown that dental pulp, periodontal ligament, and oral mucosa-derived stem/progenitor cells have the characteristics of NCSCs, with each type of tissue-derived cell considered to possess identical stem/progenitor cell properties; ${ }^{17-24,26}$ however, these differences have not been characterized. Elucidating these cell-specific characteristics may help in not only demonstrating the importance of each cell type with respect to tissue regeneration via differentiation into suitable target lineages but also identifying tissuespecific markers and their developmental role in the currently unknown human tooth developmental process.

The apical papilla, periodontal ligament, and oral mucosa can be obtained concomitantly during the extraction of an impacted third molar with an immature apex. To the best of our knowledge, differences in the differentiation ability and expression of molecular markers among human apical papilla-derived cells (APDCs), periodontal ligament-derived cells (PDLDCs), and oral mucosa stroma-derived cells (OMSDCs) obtained from individuals at the same time and from the same sites have not been reported previously. This study was performed to characterize human NCSC-like cells from tissues obtained through the extraction of impacted developing third molars and to confirm the differences in cellular characteristics and molecular markers of individual tissue-derived stem cells, which have great scope to be utilized clinically and to be potentially valuable in dental regenerative medicine.

\section{Methods}

\subsection{Patients}

This study was approved by the Institutional Review Board of Tokyo Metropolitan Hiroo Hospital (expedited approval number: 2019-15 and 2020-11), the Faculty of Dentistry of the Tokyo Medical and Dental University (approval number: D2017-036), and the Faculty of Medicine of the Nihon University (approval number: P2019-0). Thirty-one patients, aged 12 to 22 years, underwent surgery-through which human apical papilla, periodontal ligament, and oral mucosa tissues were obtained-for the extraction of impacted developing third molars that had formed approximately more than one-third of their root at the Oral Surgery Department of the Tokyo Metropolitan Hiroo Hospital and Nihon University School of Medicine. Written informed consent was obtained from all donors.

\subsection{Histological analysis}

Human apical papilla, periodontal ligament, and oral mucosa tissues were obtained from 11 randomly selected patients. Histological analysis was performed as described previously. ${ }^{23}$ The sections were then 
sliced and used for hematoxylin-eosin (H\&E) and immunohistochemical staining for nestin, CD44, CD24, and CD56 (NCAM1). Samples from seven and four patients were used to perform immunohistochemistry for nestin and CD44, and CD24 and CD56 (NCAM1), respectively.

\subsection{Cell culture}

For primary cell culture, apical papilla, periodontal ligament, and oral mucosa tissues were cut into 2-3 mm pieces, each of which was cultured in Isocove's modified Dulbecco's medium (Nacalai Tesque, Kyoto, Japan) supplemented with $10 \%$ fetal bovine serum (FBS). APDCs, PDLDCs, and OMSDCs were passaged and seeded at a density of $2.0 \times 10^{4}$ cells/well in a 6-well culture plate. ${ }^{5,6,17,18,23}$ Cryopreserved cells from the second to fifth passages were used for each experiment.

\subsection{Growth of APDCs, PDLDCs, and OMSDCs}

APDCs, PDLDCs, and OMSDCs from five patients were seeded at a density of 5,000 cells/well in 96-well plates. The cells were counted $1,3,5$, and 7 days following culture using a cell counting kit-8 (Dojindo, Tokyo, Japan) to determine the number of viable cells. ${ }^{23}$

\subsection{Colony-forming assay}

APDCs, PDLDCs, and OMSDCs from five patients were seeded at a density of 500 cells/well in 6-well plates. After 14 days of culture, the cells were stained with crystal violet. Colonies comprising at least 50 cells were counted. Experiments were performed in triplicate for each sample. Colony areas were measured using ImageJ (National Institutes of Health, Bethesda, MD, USA).

\subsection{Sphere culture}

APDCs, PDLDCs, and OMSDCs (2.0 or $5.0 \cdot 10^{4}$ cells/well) were cultured in 24-well super-hydrophilic plates (Cellseed, Tokyo, Japan) in serum-free Dulbecco's modified Eagle's medium (DMEM)/F12 (1:1) containing $\mathrm{N}_{2}$ supplements (Gibco Life Technologies, Carlsbad, CA, USA), $20 \mathrm{ng} / \mathrm{mL}$ basic fibroblast growth factor (PeproTech, Rocky Hill, NJ, USA), and 20 ng/mL epidermal growth factor (PeproTech) for 7 days. 17,18,23 Primary spheres were used for all experiments. To analyze the sphere-forming ability and measure sphere diameter, APDCs, PDLDCs, and OMSDCs (2.0 × $10^{4}$ cells/well) were cultured in 24-well super-hydrophilic plates in sphere culture conditions for 7 days. Spheres with a diameter $\geq 100 \mu \mathrm{m}$ were counted, and the diameter of all spheres was measured using ImageJ. Experiments were performed in triplicate for each sample.

\subsection{Immunohistochemistry}

Immunohistochemistry was performed as previously described. ${ }^{23}$ Tissues and cells were fixed with $4 \%$ paraformaldehyde (PFA) (Wako Pure Chemical, Osaka, Japan) at $4^{\circ} \mathrm{C}$ and washed twice with tris buffered saline with Tween ${ }^{\circledR} 20$ (TBST). The cells and cryosections were incubated in Blocking One Histo solution (Nacalai Tesque, Kyoto, Japan) for 10 min to prevent non-specific binding of the antibodies. The slides were incubated at room temperature for $1 \mathrm{~h}$ with antibodies specific for nestin (10C2; eBioscience, San Diego, CA; 1:50), CD44 (IM7; eBioscience; 1:100), CD24 (ML5; BD Pharmingen, San Jose, CA; 1:50), CD56 (B159; BD Pharmingen; 1:50), a-smooth muscle actin (a-SMA; 1A4; R\&D Systems; 1:200), ß3-tubulin (2G10; eBioscience; 
1:100), or human osteocalcin (OCN; 5-12H; Takara; 1:100). The cells were washed twice with phosphatebuffered saline (PBS) and incubated at room temperature for $30 \mathrm{~min}$ with anti-mouse IgG conjugated with Alexa Fluor 488 (Invitrogen, Carlsbad, CA, USA; 1:200) and anti-mouse or anti-rat IgG conjugated Alexa 594 (Invitrogen; 1:200). For the quantitative analysis, the percentage of positively stained areas or cells was determined by counting the number of cells or using ImageJ software in randomly selected fields or sections.

\subsection{Flow cytometry}

For cell surface antigen phenotyping, sphere-forming APDCs, PDLDCs, and OMSDCs from three patients were enzymatically dissociated and washed with PBS. To assess the expression of nestin, cells were fixed with 4\% PFA and permeabilized with ice-cold methanol. The dissociated cells were incubated at room temperature for $1 \mathrm{~h}$ with antibodies specific for nestin (10C2; eBioscience; 1:50), CD24 (ML5; BD Pharmingen, San Jose, CA, USA; 1:50), CD29 (MAR4; BD Pharmingen; 1:100), CD34 (581; BD Pharmingen; 1:100), CD44 (IM7; eBioscience; 1:100), CD45 (HI30; BD Pharmingen; 1:100), CD56 (B159; BD Pharmingen; 1:50), CD73 (AD2; BD Pharmingen; 1:100), and CD90 (5E10; BioLegend, San Diego, CA; 1:100). After incubation with the primary antibody, the cells were washed with PBS, and then incubated with anti-mouse or anti-rat IgG conjugated with Alexa 488 or 594 (Invitrogen; 1:200) at room temperature for 30 min. Subsequently, the cells were analyzed with a FACSCant ${ }^{\top}$ (BD Biosciences, NJ, USA) using the Flow Jo software.

\subsection{RNA extraction}

Total RNA was extracted from the cells using the RNeasy Mini Kit (Qiagen, Hilden, Germany), according to the manufacturer's instructions.

\subsection{Microarray}

The total RNA of sphere-forming APDCs, PDLCs, and OMSCs from three patients was used for the microarray analysis. Total RNA (100 ng) was reverse-transcribed into cDNA using the Low Input Amp Labeling Kit (Agilent Technologies, Santa Clara, CA, USA). Next, cDNA was mixed with a hybridization buffer and hybridized to a SurePrint G3 Human GE microarray 8X60k v3 (Agilent Technologies) for $17 \mathrm{~h}$ following the manufacturer's instructions. The chips were washed and subsequently scanned using the Agilent microarray scanner (Agilent Technologies). Raw data were analyzed using the feature extraction software (v.11.5.1.1; Agilent Technologies) and microarray data were mined and analyzed using GeneSpring (Agilent Technologies). The signal intensity was normalized by adjusting the data to a 75th percentile baseline (GEO accession number for the microarray gene expression data: GSE164327).

\subsection{Semi-quantitative and quantitative reverse transcription PCR (RT-PCR)}

Semi-quantitative RT-PCR was performed using the PrimeScript One-Step RT-PCR Kit Ver.2 (Takara) and 10 ng of total RNA. cDNA synthesis and pre-denaturation were performed for one cycle at $50^{\circ} \mathrm{C}$ for 30 min and $94^{\circ} \mathrm{C}$ for $2 \mathrm{~min}$. Following initial denaturation, amplification was performed over 35 cycles of $94^{\circ} \mathrm{C}$ for $30 \mathrm{~s}$, $56-58^{\circ} \mathrm{C}$ for $30 \mathrm{~s}$, and $72^{\circ} \mathrm{C}$ for $1 \mathrm{~min}$ in a SimpliAmp thermal cycler (Applied Biosystems, Life Technologies). Quantitative RT-PCR was performed using the One-Step PrimeScript RT-PCR Kit (Perfect Real 
Time; Takara). cDNA synthesis and pre-denaturation were performed over 1 cycle of $42^{\circ} \mathrm{C}$ for 5 min and $95^{\circ} \mathrm{C}$ for $10 \mathrm{~s}$. After initial denaturation, amplification was performed over 40 cycles of $95^{\circ} \mathrm{C}$ for $5 \mathrm{~s}$ and $60^{\circ} \mathrm{C}$ for $31 \mathrm{~s}$ in an Applied Biosystems 7300 real-time PCR system (Applied Biosystems, Life Technologies). The cycle threshold values (Ct values) were used to calculate the fold differences using the $2^{-\Delta \Delta \mathrm{Ct}}$ method. The primer sequences used for the RT-PCR are listed in Table $1.23,27,28$

\subsection{Differentiation of the sphere-forming APDCs, PDLDCs, and OMSDCs}

For mineralized-cell differentiation, sphere-forming APDCs, PDLDCs, and OMSDCs were seeded in 24-well plates and cultured for 7 days in a-minimum essential medium (aMEM) supplemented with 10\% FBS. Subsequently, the medium was replaced with mesenchymal stem cell (MSC) osteogenic differentiation medium (ready-to-use; Takara) supplemented with $100 \mathrm{ng} / \mathrm{mL}$ bone morphogenic protein 2 (BMP-2; PeproTech), and the cells were further cultured for up to 3 weeks. To identify the mineralized matrix, cells were stained with Alizarin Red S (Wako Pure Chemical). The stained area was then measured using ImageJ. For adipogenic differentiation, spheres were cultured as described above. The medium was then replaced with adipogenic differentiation medium, i.e., aMEM supplemented with 10\% FBS and $500 \mathrm{mM}$ 3-isobutyl-1methylxanthine (Sigma-Aldrich, St. Louis, MO), $1 \mu \mathrm{M}$ dexamethasone (Sigma-Aldrich), $0.01 \mathrm{mg} / \mathrm{mL}$ insulin (Sigma-Aldrich), and $0.2 \mathrm{mM}$ indomethacin (Sigma-Aldrich), and the spheres were incubated for up to 3 weeks. Cells were stained with Oil Red O (Sigma-Aldrich) to detect adipocyte differentiation. For chondrogenic differentiation, the spheres were cultured as described above, and the enzymatically dissociated cells $\left(2.0 \times 10^{5}\right.$ cells/tube) were maintained in MSC chondrogenic differentiation medium (readyto-use; Takara) using a pellet culture for 3 weeks, as described previously. 5,18,23 Toluidine blue (Muto Pure Chemical, Tokyo, Japan) staining was performed to identify chondrogenic cells. For myogenic differentiation, spheres were cultured as described above, prior to being cultured in high-glucose DMEM supplemented with $10 \%$ FBS and $10 \mathrm{ng} / \mathrm{mL}$ TGF- $\beta 1$ (PeproTech) for 10 days. ${ }^{17,18,23}$ To identify smooth muscle cells, cells were immunostained with anti-a-SMA antibody. For neural differentiation, after the spheres were cultured as described above, the medium was replaced with MSC neurogenic differentiation medium (ready-to-use; Takara) and the spheres were further cultured for 1 week. To identify neural cells, immunostaining with anti- $\beta 3$-tubulin antibody was conducted.

\subsection{In vivo hard tissue regeneration capacity}

All experimental procedures were approved by and conducted in accordance with the Animal Care and Committee of the Tokyo Medical and Dental University (approval number: A2019-313A). Sphere-forming APDCs, PDLDCs, and OMSDCs were cultured for 7 days in aMEM supplemented with $10 \%$ FBS.

Enzymatically dissociated cells were seeded at a density of $2.0 \times 10^{5}$ cells into porous hydroxyapatite (HA) scaffolds that were half in size (Hoya Technologies, Tokyo, Japan; 85\%, pore diameter: $100-500 \mu \mathrm{m}$, diameter: $5 \mathrm{~mm}$, and thickness: $2 \mathrm{~mm}$. Gifted by Dr. Yasuharu Yamazaki, Kitasato University School of Medicine). The cells were transplanted into immunocompromised mice 10 days after mineralization-induced cell differentiation according to the method described above $\left(n=3\right.$, patient-matched). ${ }^{6,17,18,23}$ Briefly, cells with HA scaffolds were implanted into subcutaneous pouches in the dorsum of 5-week-old male BALB/cAJcl 
nude mice (CLEA Japan, Tokyo, Japan). After 12 weeks, the implanted tissues were removed and prepared for histological analysis as described previously. ${ }^{6,17,18}$

\subsection{Scanning electron micrograph (SEM) analysis}

SEM analysis was performed as previously described. 6,23

\subsection{Statistical analysis}

Mean values were compared using one-way analysis of variance with post hoc Tukey's multiple comparison test. $P<0.05$ was considered significant. All statistical analyses were performed using EZR (Saitama Medical Center, Jichi Medical University, Shimotsuke, Japan), a graphical user interface for R (version 2.13.0, R Foundation for Statistical Computing, Vienna, Austria).

\section{Results}

\subsection{Clinical and histological features of human apical papilla, periodontal ligament, and oral mucosa tissue}

The developing impacted third molar had an immature apex (Fig. 1a, b). The apical papilla was the soft tissue of the apical tip of immature roots (Fig. 1a, c), whereas the periodontal ligament was the thin, soft tissue between the cementum and alveolar bone (Fig. 1a, d). The periodontal ligament tissue did not fuse to the apical papilla tissue and was easily peeled off, thereby enabling the collection of only the periodontal ligament tissue (Fig. 1d). The oral mucosal covering of the oral cavity obtained during molar extraction was the gingiva or alveolar mucosa (Fig. 1a, c). To investigate the candidate niche of NCSCs, tissue sections were stained for nestin and CD44. ${ }^{23}$ Double-positive cells were observed in the dentin-apical pulp junction of the apical papilla, some areas of the periodontal ligament, and the lamina propria of the oral mucosa (Fig. 1e).

\subsection{Culturing of APDCs, PDLDCs, and OMSDCs}

Primary cells were cultured using the outgrowth culture system. ${ }^{5,6,17,18,23}$ Fibroblastic cells were observed around the plated tissue (Fig. 2a). The cells were then passaged (Fig. 2a). Differences in morphological features were not observed between the tissues. The APDCs, PDLDCs, and OMSDCs grew rapidly in an in vitro monolayer culture (Fig. 2a). No significant difference was observed in the growth curves of cells derived from each tissue on each day (Fig. 2b). Furthermore, 500 cells formed adherent colonies on day 14, which were stained with crystal violet (Fig. 2c). APDCs and OMSDCs differed significantly in their colony-forming abilities ( $P=0.016$; Fig. $2 \mathrm{~d}$ ). However, colony area measurement revealed that APDCs tended to form large colonies, whereas OMSDCs formed small colonies (Fig. 2e).

\subsection{Expression of NCSC and MSC markers in APDCs, PDLDCs, and OMSDCs}


Immunohistochemical and flow cytometric analyses were performed to evaluate the expression of NCSC or MSC markers in APDCs, PDLDCs, and OMSDCs. Expanded APDCs, PDLDCs, and OMSDCs were positive for nestin and CD44 (Fig. 2f). Flow cytometry analysis indicated that most cells derived from each tissue were positive for nestin and CD44 (Fig. 2g). Nestin-positive cells accounted for $87.9 \%, 82.5 \%$, and $88.5 \%$ of APDCs, PDLDCs, and OMSDCs, respectively, whereas CD44-positive cells accounted for $90.9 \%, 84.1 \%$, and $85.6 \%$ of APDCs, PDLDCs, and OMSDCs, respectively. Double-positive cells accounted for $86.7 \%, 79.8 \%$, and $84.4 \%$ of APDCs, PDLDCs, and OMSDCs, respectively. The expression of these markers did not vary significantly among the cell types (Fig. $2 \mathrm{~h}$ ). Furthermore, these cells were positive for nearly all MSC markers (CD29, CD73, and CD90); however, they were negative for CD34 and CD45, indicating that they were not of hematopoietic stem/progenitor cell origin (Fig. 2i).

\subsection{Characteristics of spheres derived from APDCs, PDLDCs, and OMSDCs}

To enrich NCSC-like cells, APDCs, PDLDCs, and OMSDCs were cultured using the sphere technique (Fig. 3a). The average number of spheres (diameter $\geq 100 \mu \mathrm{m}$ ) was $6.92 \pm 0.56$ for APDCs, $6.64 \pm 0.58$ for PDLDCs, and $5.64 \pm 0.58$ for OMSDCs (Fig. 3b). The sphere-forming ability did not differ significantly between cells derived from different tissues (Fig. 3b). Measurement of sphere diameter revealed the same tendency in each tissue and that spheres with a diameter of 100-200 $\mu \mathrm{m}$ were the most frequent (Fig. 3c). The isolated sphere-forming APDCs, PDLDCs, and OMSDCs expressed neural stem cell (NSC)- and NCSC-specific markers, such as NES, CD44, SNAI1, SNAI2, MSX1, and HES1, as shown by semi-quantitative RT-PCR (Fig. 3d) and immunohistochemistry for nestin and CD44 (Fig. 3e).

\subsection{Differentiation into NC lineage cells}

Sphere-forming APDCs, PDLDCs, and OMSDCs exhibited the multipotency of NCSCs (Fig. 4), as they differentiated into mesenchymal lineage cells and neuronal lineage cells under appropriate culture conditions. In mineralized-cell differentiation, the Alizarin Red-stained areas in APDCs and PDLDCs were significantly higher than those in OMSDCs ( $P=0.025$ and $P=0.013$, respectively; Fig. 4a[a, b]). Furthermore, quantification of the expression of mineralized-cell differentiation markers revealed that $R U N X 2$, a master gene regulating mineralization, was expressed in APDCs, PDLDCs, and OMSDCs (Fig. 4a[c]), suggesting that these cells were able to differentiate into mineralized progenitor cells. However, $S P 7$, which is a late mineralized-cell differentiation marker, was detected in APDCs and PDLSCs, not in OMSDCs (Fig. 4a[c]). In chondrogenic differentiation, these pellets were stained with toluidine blue (Fig. $4 \mathrm{~b}[\mathrm{a}, \mathrm{b}]$ ). Expression of chondrogenesis-related markers (CHAD and COL2A) was confirmed in APDCs, PDLDCs, and OMSDCs (Fig. 4b[c, d]), which did not vary significantly between tissues. After adipogenic differentiation, Oil Red Opositive adipocytes were observed in all cells (Fig. 4c[a]), although the number of differentiated adipocytes was higher in OMSDCs than in APDCs and PDLDCs. The expression of adipogenesis-related markers (PPARG and $L P L$ ) was significantly upregulated in OMSDCs compared with that in APDCs and PDLDCs (PPARG: $P=0.0002$ and $P=0.006$, respectively; $L P L: P=0.012$ and $P=0.027$, respectively; Fig. $4 \mathrm{c}[\mathrm{b}, \mathrm{c}]$ ). In smooth muscle cell differentiation, all tissue-derived cells differentiated into a-SMA-positive smooth muscle cells (Fig. 4d[a]). ACTA2 (mRNA) and a-SMA (protein) expression levels were determined in all cells 
(Fig. 4d[b, c]) and found to not vary significantly between tissues. During neuronal differentiation, all tissuederived cells changed into multipolar morphological cells (Fig. 4e[a]) and differentiated into $\beta 3$-tubulinpositive neuronal cells (Fig. 4e[b]). TUBB3 (mRNA) and $\beta 3$-tubulin (protein) expression was confirmed in all cells (Fig. $4 \mathrm{e}[\mathrm{c}, \mathrm{d}]$ ) and did not vary significantly between tissues. The in vitro differentiation assay indicated that the sphere-forming cells contained NCSCs. APDCs and PDLDCs readily differentiated into mineralized cells; however, their differentiation into adipocytes was more difficult. Moreover, OMSDCs exhibited opposite differentiation abilities.

\subsection{Generation of hard tissue in vivo}

To investigate the regeneration capacity of sphere-forming APDCs, PDLDCs, and OMSDCs related to the formation of hard tissue in vivo, composites of osteogenesis-inducing cells and a multiporous HA scaffold were implanted subcutaneously into immunocompromised mice (Fig. 5a). To investigate cell adhesion to the multiporous HA scaffolds, the sphere-forming cells cultured on the scaffolds were examined by SEM 10 days after seeding (Fig. 5a). The sphere-forming cells from all tissues showed vigorous cell sheet-like growth in the multiporous scaffold (Fig. 5a). Twelve weeks after implantation, APDCs, PDLDCs, and OMSDCs had formed ectopic mature or immature hard tissue (Fig. 5b). The regenerated hard tissues were osteodentin-like in nature, and did not form lamellar bone structures in APDCs, thin cellular or acellular cementum-like tissues in PDLDCs, and thin immature osteoid-like tissues in OMSDCs (Fig. 5b). Masson's trichrome staining revealed that these regenerated hard tissues comprised collagen fibers (Fig. 5b). Regenerated hard tissue stained positively for anti-human OCN (Fig. 5b). These data suggested that the regenerated tissue was hard tissue. Next, the ability to form hard tissue was quantified using the hard tissue area stained with H\&E (Fig. 5c) and the OCN-positive area (Fig. 5d). APDCs exhibited a significantly larger area of hard tissue formation ( $P=0.004, P=0.003$ respectively) and $0 \mathrm{CN}$ expression $(P=0.007, P=0.004$ respectively) than PDLDCs and OMSDCs (Fig. 5c, d).

\subsection{Transcriptome changes in sphere-forming APDCs, PDLDCs, and OMSDCs}

To characterize the gene expression profiles of sphere-forming cells, microarray analysis was performed and the expression profiles of sphere-forming APDCs, PDLDCs, and OMSDCs were compared. Significantly differentially expressed genes (DEGs) were also identified in these cells and clustered into three groups (Fig. 6a): group 1 comprised 37 genes highly enriched in sphere-forming APDCs, group 2 contained 160 genes that were highly enriched in both sphere-forming APDCs and PDLDCs compared with OMSDCs, and group 3 comprised 123 genes enriched in sphere-forming OMSDCs compared with APDCs and PDLDCs (Fig. 6a). Only two genes were enriched in PDLDCs compared with APDCs and OMSDCs. Of the significant DEGs, CD24 (group 1); CD56 (NCAM1), LRRC17, KCNK12, and HAPLN1 (groups 2); and SUSD2, PTPRE, $F B L N 2$, and $D L L 1$ (group 3) were selected and identified among the common genes with different levels of expression in the top 10 genes data compared between groups (Fig. 6b, Supplemental Table 1). The results of quantitative RT-PCR confirmed the results of the microarray analysis (Fig. 6c). Only SUSD2 expression was upregulated in the oral mucosa of all samples, although not significantly (Fig. 6c). Furthermore, flow cytometric analysis was performed for CD24 and CD56 (NCAM1) in sphere-forming cells (Fig. 6d). CD24 
expression was observed in $2.93 \% \pm 1.10 \%$ of APDCs but not in PDLDCs or OMSDCs (Fig. 6d). CD56 (NCAM1) expression was observed in $9.59 \% \pm 2.16 \%$ of APDCs and $3.98 \% \pm 0.69 \%$ of PDLDCs but not in OMSDCs (Fig. 6d). Surprisingly, immunohistochemical analyses of CD24 and CD56 (NCAM1) in human tissues revealed that CD24 was expressed in the apical papilla, whereas CD56 (NCAM1) was expressed in the apical papilla and periodontal ligament. In the oral mucosa, the expression of CD24 was observed only in the oral epithelium, whereas that of CD24 and CD56 (NCAM1) was not detected in the lamina propria (Fig. 6e). These results indicated that the expression patterns of CD24 and CD56 (NCAM1) varied with tissues and that they may serve as candidate markers for tissue specificity.

\section{Discussion}

To date, specific markers for the localization of NCSCs in human tissues have not been identified. Previously, we reported that nestin ${ }^{+} / \mathrm{CD} 44^{+}$cells are localized in the lamina propria of the oral mucosa. ${ }^{23}$ Nestin is a widely used NSC and stem cell marker in the dental pulp (including apical papilla) ${ }^{3,5,17-19}$, periodontal ligament, ${ }^{22}$ oral mucosa/gingiva, ${ }^{9,11,23,24}$ skin, ${ }^{12,13,15,16}$ heart, ${ }^{15}$ and bone marrow. ${ }^{16}$ Previous reports have suggested that nestin-positive bone marrow cells are enriched multipotent MSCs with sphere-forming and self-renewing abilities. ${ }^{29-31}$ Although nestin is expressed in NSCs, Liu et al. reported that human embryonic stem cell-derived NCSCs are nestin ${ }^{+} / \mathrm{CD} 44^{+}$, whereas NSCs are nestin ${ }^{+} / \mathrm{CD} 44^{-} .32$ Therefore, both nestin and CD44 were utilized to identify NCSCs; a nestin ${ }^{+} / \mathrm{CD} 44^{+}$population was observed among the cells derived from each tissue. Surprisingly, most cells were nestin ${ }^{+} / \mathrm{CD}_{4} 4^{+}$(approximately $80 \%-87 \%$ ), although they may have been derived from NCs.

In this study, the cells did not differ in proliferative capacity, although OMSDCs had significantly higher colony-forming ability than APDCs (Fig. 2b-d). Previously, several reports suggested a lack of difference in the colony-forming abilities of DPSCs, PDSCs, and gingival mesenchymal stem cells (GMSCs), whereas others have shown that GMSCs form more colonies than DPSCs and PDLSCs. ${ }^{33-36}$ The colony-forming abilities of these cells correlate with their proliferative capability, although the colony details have not been assessed. ${ }^{33-36}$ Measurement of the colony area in this study showed that APDCs tended to have a larger distribution area in the histogram than OMSDCs (Fig. 2e). This observation was consistent with the low colony-forming ability and high proliferation rate of APDCs.

The sphere culture system has been widely used for the enrichment of NSCs and other types of stem cells. ${ }^{37,38}$ Many reports have suggested that NCSCs, MSCs, and cancer stem cells possess sphere-forming abilities. ${ }^{13-24,30,31,38}$ Furthermore, sphere-forming APDCs, PDLDCs, and OMSDCs express NES (NSC and NCSC markers), CD44 (a possible maker of NCSC-like cells from neuroblastoma), SNA/1 (a marker for the appearance of NC or their precursors in the neural plate border), SNAI2 (a marker of epithelial-mesenchymal transition in the NC), MSX1 (a neural plate border induction marker), and HES1 (the transcription factor for Notch effectors; Notch signaling is activated during NC differentiation). ${ }^{23,39}$ These data suggest that NCderived cells or NCSCs are present in sphere-forming APDCs, PDLDCs, and OMSDCs. 
Human stem/progenitor cells derived from APDCs, PDLDCs, and OMSDCs can differentiate into NC lineage cells in vitro. ${ }^{1-9,17-24}$ However, whether the multipotency of each tissue-derived stem/progenitor cell type is equivalent was unclear. In this study, we evaluated these cells from the same individual and observed that the in vitro differentiation abilities of APDCs and PDLDCs were similar, and that the mineralized-cell differentiation abilities of these cells were high, although their adipogenic ability was low (Fig. 4a, c). OMSDCs showed the opposite tendency (Fig. 4a, c). Lei et al. reported that the expression pattern of differentiation markers in mineralized cells, adipocytes, and chondrocytes differentiated from the DPSCs and PDLSCs does not differ. ${ }^{34}$ Yang et al. compared the multipotency of PDLSCs and gingiva-derived MSCs (GMSCs) and observed that PDLSCs have a higher ability to differentiate into mineralized cells and chondrocytes than GMSCs and that there is no significant difference in their abilities to differentiation into adipocytes. ${ }^{33}$ Monterubbianes et al. reported that GMSCs have a higher adipogenic differentiation ability than DPSCs and that DPSCs exhibit a higher osteogenic potential than GMSCs. ${ }^{40}$ A comparative study of abilities for differentiation into smooth muscle cells and neuronal cells in these cells is lacking. Our results regarding mineralized-cell and adipocyte differentiation abilities were similar to those reported by Monterubbianes et al. However, we did not observe any difference in chondrocyte differentiation between tissues. Previous studies isolated these stem/progenitor cells through monolayer culture, whereas we used enriched stem/progenitor cells isolated using the sphere culture technique in this study. We believe that differentiation abilities may differ with the stem/progenitor cell isolation technique.

The in vivo hard tissue regenerative capacity of APDCs, PDLDCs, and OMSDCs has been reported previously. ${ }^{1-9,17-23}$ Previously, we reported that not only APDCs but also OMSDCs regenerate into hard tissue when transplanted subcutaneously into immunodeficient mice following culture in BMP-2supplemented mineralization-inducing cell differentiation medium. 5,6,17,18,23 Although human APDCs retained osteodentin-like hard tissue-forming abilities, PDLDCs and OMSDCs had negligible hard tissueforming ability (Fig. 6). Surprisingly, PDLDCs showed different hard tissue-forming abilities in in vitro and in vivo transplantation experiments. Grzesik et al. reported that hard tissue is not formed upon transplantation of PDLDCs, although these cells form calcified nodules and express mineralized-cell differentiation markers when cultured in mineralized-cell differentiation medium in vitro. ${ }^{41}$ Seo et al. reported that, unlike DPSCs, PDLSCs have the potential to generate cementum/PDL-like tissue, in which hard tissue is thinly formed around HA in vivo. ${ }^{7}$ Grzesik et al. suggested that differentiated mineralized cells are lost in the early stage of differentiation and that the remaining cells do not form hard tissue in vivo; alternatively, the differentiated mineralized cells may be negatively regulated by other fibroblastic populations that exert a suppressive influence in vivo. ${ }^{41,42}$ In the present study, APDCs, PDLDCs, and OMSDCs were cultured in BMP-2supplemented osteogenic differentiation medium. Hence, the mineralized cells differentiated from PDLDCs may require BMP-2 and might have formed hard tissue only when it was supplied as a stimulus. ${ }^{41}$ The difference in the ability of each tissue-derived cell to form hard tissue in vivo is closely associated with biological roles. That is, APDCs have a high ability to form hard tissues, as they form tooth roots. In contrast, in the periodontal ligament, the ability to form cementum remains unaltered, despite the application of occlusal force. In addition, ectopic bone formation in the oral mucosa is extremely rare. 
We detected genes with different expression levels among distinct tissue-derived cells. CD24 has been reported as a marker of several normal tissue-derived stem/progenitor cells and cancer stem cells. ${ }^{20}$ These $^{2}$ stem/progenitor cells show higher CD24 expression than terminally differentiated cells, revealing the close relationship between CD24 expression and cellular pluripotency and self-renewal capability. ${ }^{20}$ This phenomenon has been reported in previous studies on tooth development. For example, Sonoyama et al. reported that CD24 is a specific marker of the apical papilla, whereas it is not detected in DPSCs and bone marrow MSCs, and that mineralized cells differentiated from APDCs do not express CD24. ${ }^{4}$ Recently, Chen et al. reported that CD24 expression increases by $72.9 \%$ during sphere formation in mouse APDCs. ${ }^{20}$ However, in our study, the expression of CD24 in sphere-forming human APDCs was only 2.9\% (Fig. 6). Similar to our results, Sonoyama et al. reported an average of $7.56 \%$ for their CD24-positive cells. ${ }^{4}$ Hence, further studies regarding the expression of CD24 in APDCs are required. CD56 (NCAM1) is a marker of natural killer cells, neural cells, muscles, and MSCs generated from human embryonic stem cells. ${ }^{43,44}$ Surprisingly, Buttula et al. detected adipocyte differentiation in colonies derived from MSCA- $1^{+} / \mathrm{CD}_{56}{ }^{-} \mathrm{MSC}$ but not from MSCA$1^{+} / \mathrm{CD}^{+} 6^{+} \mathrm{MSCs} .{ }^{44}$ This was consistent with the fact that CD56- ${ }^{-}$MSDCs show significantly higher adipocyte differentiation than $\mathrm{CD}^{+} 6^{+}$APDCs and PDLDCs.

HAPLN1 regulates cell growth in developing cartilage and heart valves and is expressed in mesodermcommitted cells derived from embryonic stem cells, cancer cells undergoing epithelial-mesenchymal transition (EMT), and metastatic melanomas. ${ }^{45}$ Mabarki et al. reported that HAPLN1 is expressed de novo in EPCAM1 ${ }^{-} / \mathrm{CD} 56(\mathrm{NCAM} 1)^{+}$mesoderm-committed progenitor cells and fibroblastic hepatocellular carcinoma cells and during the dedifferentiation of hepatocyte-like cells to liver progenitors and that silencing HAPLN1 downregulates the markers of EMT. ${ }^{45}$ As sphere-forming APDCs and PDLDCs expressed HAPLN1 and CD56, these markers may be related in MSCs, cells undergoing EMT, and NCSCs (Fig. 6c-e). Kim et al. reported that LRRC17, a member of the LRR superfamily, acts as a negative regulator of RANKL-induced osteoclast differentiation and is highly expressed in osteoblasts. ${ }^{46}$ This is consistent with its significantly high expression levels in APDCs and PDLDCs, which tend to differentiate more into mineralized cells in vitro than OMSDCs (Fig. 4a).

The roles of the other genes with significant differences in expression levels are unknown, and further investigations are warranted. Although it was difficult to identify stem cell-specific markers based only on the characteristic markers identified in this study, we successfully determined the specific markers for each tissue and tissue-derived cell.

The minimum defining criteria for MSCs are that they attach to a plastic cell culture dish, express MSC surface markers, and exhibit multipotency. ${ }^{47}$ Sacchetti et al. reported that MSCs obtained from different sites differ in their multilineage differentiation abilities and retain lineage-committed properties despite being isolated using certain MSC markers. ${ }^{48}$ Although previous reports suggest that human "NCSC-like cells" have been defined based on their sphere-forming capacity, expression of NCSC-related markers, and in vitro multipotential phenotype, this study also showed that the differentiation potential and expression of markers differed in distinct tissue-derived cells, depending on the tissue from which the cells were obtained, and that their characteristics should be considered during application in regenerative medicine. ${ }^{13,18,21,23,24,39}$ In the 
future, these distinct tissue-specific markers may play a crucial role in tooth regenerative medicine as they can clearly distinguish each tissue in the tooth organoids generated using induced pluripotent stem cells and tissue-derived stem/progenitor cells.

\section{Conclusions}

We demonstrated that multilineage sphere-forming APDCs, PDLDCs, and OMSDCs share the same phenotypes as other stem/progenitor cells, although the expression of certain tissue-specific markers and the differentiating abilities vary. We showed for the first time that APDCs, PDLDCs, and OMSDCs obtained from the same patients and, concomitantly, the same sites can be used individually in regenerative medicinebased therapy. Additionally, we identified human tissue-specific markers in the currently unknown human tooth developmental process.

\section{Abbreviations}

Neural crest-derived stem cell (NCSC), multilineage sphere-forming apical papilla-derived cells (APDCs), periodontal ligament-derived cells (PDLDCs), oral mucosa stroma-derived cells (OMSDCs), dental pulp stem cells (DPSCs), periodontal ligament stem cells (PDLSCs), oral mucosa stromal stem cells (OMSCs), hematoxylin-eosin (H\&E), fetal bovine serum (FBS), Dulbecco's modified Eagle's medium (DMEM), paraformaldehyde (PFA), tris buffered saline with Tween ${ }^{\circledR} 20$ (TBST), phosphate-buffered saline (PBS), a-minimum essential medium (aMEM), bone morphogenic protein 2 (BMP-2), differentially expressed genes (DEGs), gingival mesenchymal stem cells (GMSCs)

\section{Declarations}

\section{Ethics approval and consent to participate}

This study was approved by the Institutional Review Board of Tokyo Metropolitan Hiroo Hospital (expedited approval number: 2019-15 and 2020-11), the Faculty of Dentistry of the Tokyo Medical and Dental University (approval number: D2017-036), and the Faculty of Medicine of the Nihon University (approval number: P2019-0). Written informed consent was obtained from all donors. All experimental procedures were approved by and conducted in accordance with the Animal Care and Committee of the Tokyo Medical and Dental University (approval number: A2019-313A).

\section{Consent for publication}

Not applicable.

\section{Availability of data and materials}

The raw and processed microarray data required to reproduce these findings are available from GSE164327.

\section{Competing interests}


The authors declare that they have no competing interests.

\section{Funding}

This work was supported by Grants-in-Aid for Scientific Research (C) [grant numbers 16K11644 and 19K10183] from the Ministry of Education, Culture, Sports, Science and Technology of Japan.

\section{Authors' contributions}

SA contributed to study conception and design, methodology, investigation, data analysis and interpretation, and manuscript writing. AK and KN contributed to study conception and design, methodology, investigation, and data analysis and interpretation. NY and YK contributed to study conception and design, methodology, and investigation. $\mathrm{MM}, \mathrm{TM}, \mathrm{CH}, \mathrm{HK}$, and TY contributed to study conception and design and methodology. All authors read and approved the final manuscript.

\section{Acknowledgments}

We thank Editage (www.editage.com) for English language editing.

\section{References}

1. Gronthos S, Mankani M, Brahim J, Robey PG, Shi S. Postnatal human dental pulp stem cells (DPSCs) in vitro and in vivo. Proc Natl Acad Sci U S A. 2000;97:13625-30.

2. Gronthos S, Brahim J, Li W, Fisher LW, Cherman N, Boyde A, et al. Stem cell properties of human dental pulp stem cells. J Dent Res. 2002;81:531-5.

3. Miura M, Gronthos S, Zhao M, Lu B, Fisher LW, Robey PG, et al. SHED: stem cells from human exfoliated deciduous teeth. Proc Natl Acad Sci U S A. 2003;100:5807-12.

4. Sonoyama W, Liu Y, Fang D, Yamaza T, Seo BM, Zhang C, et al. Mesenchymal stem cell-mediated functional tooth regeneration in swine. PLoS One. 2006;1:e79.

5. Abe S, Yamaguchi S, Amagasa T. Multilineage cells from apical pulp of human tooth with immature apex. Oral Sci Int. 2007;4:45-58.

6. Abe S, Yamaguchi S, Watanabe A, Hamada K, Amagasa T. Hard tissue regeneration capacity of apical pulp derived cells (APDCs) from human tooth with immature apex. Biochem Biophys Res Commun. 2008;371:90-3.

7. Seo BM, Miura M, Gronthos S, Bartold PM, Batouli S, Brahim J, et al. Investigation of multipotent postnatal stem cells from human periodontal ligament. Lancet. 2004;364:149-55.

8. Fournier BP, Ferre FC, Couty L, Lataillade JJ, Gourven M, Naveau A, et al. Multipotent progenitor cells in gingival connective tissue. Tissue Eng Part A. 2010;16:2891-9.

9. Marynka-Kalmani K, Treves S, Yafee M, Rachima H, Gafni Y, Cohen MA, et al. The lamina propria of adult human oral mucosa harbors a novel stem cell population. Stem Cells. 2010;28:984-95.

10. Chai $Y$, Jiang $X$, Ito $Y$, Bringas $P$ Jr, Han J, Rowitch DH, et al. Fate of the mammalian cranial neural crest during tooth and mandibular morphogenesis. Development. 2000;127:1671-9. 
11. Xu X, Chen C, Akiyama K, Chai Y, Le AD, Wang Z, et al. Gingivae contain neural-crest- and mesodermderived mesenchymal stem cells. J Dent Res. 2013;92:825-32.

12. Fernandes KJ, McKenzie IA, Mill P, Smith KM, Akhavan M, Barnabé-Heider F, et al. A dermal niche for multipotent adult skin-derived precursor cells. Nat Cell Biol. 2004;6:1082-93.

13. Toma JG, McKenzie IA, Bagli D, Miller FD. Isolation and characterization of multipotent skin-derived precursors from human skin. Stem Cells. 2005;23:727-37.

14. Wong CE, Paratore C, Dours-Zimmermann MT, Rochat A, Pietri T, Suter U, et al. Neural crest-derived cells with stem cell features can be traced back to multiple lineages in the adult skin. J Cell Biol. 2006;175:1005-15.

15. Tomita Y, Matsumura K, Wakamatsu Y, Matsuzaki Y, Shibuya I, Kawaguchi H, et al. Cardiac neural crest cells contribute to the dormant multipotent stem cell in the mammalian heart. J Cell Biol. 2005;170:1135-46.

16. Nagoshi N, Shibata S, Kubota Y, Nakamura M, Nagai Y, Satoh E, et al. Ontogeny and multipotency of neural crest-derived stem cells in mouse bone marrow, dorsal root ganglia, and whisker pad. Cell Stem Cell. 2008;2:392-403.

17. Abe S, Hamada K, Yamaguchi S, Amagasa T, Miura M. Characterization of the radioresponse of human apical papilla-derived cells. Stem Cell Res Ther. 2011;2:2.

18. Abe S, Hamada K, Miura M, Yamaguchi S. Neural crest stem cell property of apical pulp cells derived from human developing tooth. Cell Biol Int. 2012;36:927-36.

19. Pisciotta A, Bertoni L, Riccio M, Mapelli J, Bigiani A, La Noce M, et al. Use of a 3D floating sphere culture system to maintain the neural crest-related properties of human dental pulp stem cells. Front Physiol. 2018;9:547.

20. Chen H, Fu H, Wu X, Duan Y, Zhang S, Hu H, et al. Regeneration of pulpo-dentinal-like complex by a group of unique multipotent CD24a + stem cells. Sci Adv. 2020;6:eaay1514.

21. Osathanon T, Manokawinchoke J, Nowwarote N, Aguilar P, Palaga T, Pavasant P. Notch signaling is involved in neurogenic commitment of human periodontal ligament-derived mesenchymal stem cells. Stem Cells Dev. 2013;22:1220-31.

22. Huang L, Liang J, Geng Y, Tsang WM, Yao X, Jhanji V, et al. Directing adult human periodontal ligamentderived stem cells to retinal fate. Invest Ophthalmol Vis Sci. 2013;54:3965-74.

23. Abe S, Yamaguchi S, Sato Y, Harada K. Sphere-derived multipotent progenitor cells obtained from human oral mucosa are enriched in neural crest cells. Stem Cells Transl Med. 2016;5:117-28.

24. Fournier BP, Loison-Robert LS, Ferré FC, Owen GR, Larjava H, Häkkinen L. Characterisation of human gingival neural crest-derived stem cells in monolayer and neurosphere cultures. Eur Cell Mater. 2016;31:40-58.

25. Lee G, Kim H, Elkabetz Y, Al Shamy G, Panagiotakos G, Barberi T, et al. Isolation and directed differentiation of neural crest stem cells derived from human embryonic stem cells. Nat Biotechnol. 2007;25:1468-75.

26. Tomokiyo A, Hynes K, Gronthos S. Is there a role for neural crest stem cells in periodontal regeneration? Curr Oral Health Rep. 2015;2:275-81. 
27. Xia Y, Nivet E, Sancho-Martinez I, Gallegos T, Suzuki K, Okamura D, et al. Directed differentiation of human pluripotent cells to ureteric bud kidney progenitor-like cells. Nat Cell Biol. 2013;15:1507-15.

28. Ali H, Al-Yatama MK, Abu-Farha M, Behbehani K, Al Madhoun A. Multi-lineage differentiation of human umbilical cord Wharton's Jelly Mesenchymal Stromal Cells mediates changes in the expression profile of stemness markers. PLoS One. 2015;10:e0122465.

29. lern J, García-García A, Martín AM, Arranz L, Martín-Pérez D, Torroja C, et al. The neural crest is a source of mesenchymal stem cells with specialized hematopoietic stem cell niche function. Elife. 2014;3:e03696.

30. Méndez-Ferrer S, Michurina TV, Ferraro F, Mazloom AR, Macarthur BD, Lira SA, et al. Mesenchymal and haematopoietic stem cells form a unique bone marrow niche. Nature. 2010;466:829-34.

31. Isern J, Martín-Antonio B, Ghazanfari R, Martín AM, López JA, del Toro R, et al. Self-renewing human bone marrow mesenspheres promote hematopoietic stem cell expansion. Cell Rep. 2013;3:1714-24.

32. Liu Q, Spusta SC, Mi R, Lassiter RN, Stark MR, Höke A, et al. Human neural crest stem cells derived from human ESCs and induced pluripotent stem cells: induction, maintenance, and differentiation into functional Schwann cells. Stem Cells Transl Med. 2012;1:266-78.

33. Yang H, Gao LN, An Y, Hu CH, Jin F, Zhou J, et al. Comparison of mesenchymal stem cells derived from gingival tissue and periodontal ligament in different incubation conditions. Biomaterials. 2013;34:7033-47.

34. Lei M, Li K, Li B, Gao LN, Chen FM, Jin Y. Mesenchymal stem cell characteristics of dental pulp and periodontal ligament stem cells after in vivo transplantation. Biomaterials. 2014;35:6332-43.

35. Gao Y, Zhao G, Li D, Chen X, Pang J, Ke J. Isolation and multiple differentiation potential assessment of human gingival mesenchymal stem cells. Int J Mol Sci. 2014;15:20982-96.

36. Li J, Xu SQ, Zhao YM, Yu S, Ge LH, Xu BH. Comparison of the biological characteristics of human mesenchymal stem cells derived from exfoliated deciduous teeth, bone marrow, gingival tissue, and umbilical cord. Mol Med Rep. 2018;18:4969-77.

37. Reynolds BA, Weiss S. Generation of neurons and astrocytes from isolated cells of the adult mammalian central nervous system. Science. 1992;255:1707-10.

38. Zhou X, Wang G, Sun Y. A reliable parameter to standardize the scoring of stem cell spheres. PLoS One. 2015;10:e0127348.

39. Vega FM, Colmenero-Repiso A, Gómez-Muñoz MA, Rodríguez-Prieto I, Aguilar-Morante D, Ramírez G, et al. CD44-high neural crest stem-like cells are associated with tumour aggressiveness and poor survival in neuroblastoma tumours. EBioMedicine. 2019;49:82-95.

40. Monterubbianesi R, Bencun M, Pagella P, Woloszyk A, Orsini G, Mitsiadis TA. A comparative in vitro study of the osteogenic and adipogenic potential of human dental pulp stem cells, gingival fibroblasts and foreskin fibroblasts. Sci Rep. 2019;9:1761.

41. Grzesik WJ, Kuzentsov SA, Uzawa K, Mankani M, Robey PG, Yamauchi M. Normal human cementumderived cells: isolation, clonal expansion, and in vitro and in vivo characterization. J Bone Miner Res. 1998;13:1547-54. 
42. Ogiso B, Hughes FJ, Melcher AH, McCulloch CA. Fibroblasts inhibit mineralised bone nodule formation by rat bone marrow stromal cells in vitro. J Cell Physiol. 1991;146:442-50.

43. Evseenko D, Zhu Y, Schenke-Layland K, Kuo J, Latour B, Ge S, et al. Mapping the first stages of mesoderm commitment during differentiation of human embryonic stem cells. Proc Natl Acad Sci U S A. 2010;107:13742-7.

44. Battula VL, Treml S, Bareiss PM, Gieseke F, Roelofs $H$, de Zwart P, et al. Isolation of functionally distinct mesenchymal stem cell subsets using antibodies against CD56, CD271, and mesenchymal stem cell antigen-1. Haematologica. 2009;94:173-84.

45. Mebarki S, Désert R, Sulpice L, Sicard M, Desille M, Canal F, et al. De novo HAPLN1 expression hallmarks Wnt-induced stem cell and fibrogenic networks leading to aggressive human hepatocellular carcinomas. Oncotarget. 2016;7:39026-43.

46. Kim T, Kim K, Lee SH, So HS, Lee J, Kim N, et al. Identification of LRRc17 as a negative regulator of receptor activator of NF-kappaB ligand (RANKL)-induced osteoclast differentiation. J Biol Chem. 2009;284:15308-16.

47. Dominici M, Le Blanc K, Mueller I, Slaper-Cortenbach I, Marini F, Krause D, et al. Minimal criteria for defining multipotent mesenchymal stromal cells. The International Society for Cellular Therapy position statement. Cytotherapy. 2006;8:315-7.

48. Sacchetti B, Funari A, Remoli C, Giannicola G, Kogler G, Liedtke S, et al. No identical "mesenchymal stem cells" at different times and sites: Human committed progenitors of distinct origin and differentiation potential are incorporated as adventitial cells in microvessels. Stem Cell Rep. 2016;6:897-913.

\section{Tables}


Table 1

Primers used for RT-PCR

\begin{tabular}{|c|c|c|c|c|c|}
\hline \multirow[t]{2}{*}{ Gene } & & \multirow[t]{2}{*}{ Primer/Probe sequence ( $5^{\prime}$ to $\left.3^{\prime}\right)$} & \multirow[t]{2}{*}{ GenBank } & \multirow{2}{*}{$\begin{array}{l}\text { Size } \\
\text { (bp) }\end{array}$} & \multirow{2}{*}{$\begin{array}{l}\text { Reference } \\
\text { Primer bank } \\
\text { ID/Assay name }\end{array}$} \\
\hline & & & & & \\
\hline \multirow[t]{2}{*}{ NES } & $\mathrm{F}$ & CCTGGGAAAGGGAGA GTACC & NM_006617 & 111 & [27] \\
\hline & $\mathrm{R}$ & TGGTCCTTCTCCACCGTA TC & & & \\
\hline \multirow[t]{2}{*}{$C D 44$} & $\mathrm{~F}$ & CTGCCGCTTTGCAGGTGTA & NM_000610 & 109 & [28] \\
\hline & $\mathrm{R}$ & CATTGTGGGCAAGGTGCTATT & & & \\
\hline \multirow[t]{2}{*}{ SNA/1 } & $\mathrm{F}$ & TCGGAAGCCTAACTACAGCGA & NM_005985 & 140 & 301336132c1 \\
\hline & $\mathrm{R}$ & AGATGAGCATTGGCAGCGAG & & & \\
\hline \multirow[t]{2}{*}{ SNAI2 } & $\mathrm{F}$ & TGTGACAAGGAATATGTGAGCC & NM_003068 & 203 & $324072669 c 2$ \\
\hline & $\mathrm{R}$ & TGAGCCCTCAGATTTGACCTG & & & \\
\hline \multirow[t]{2}{*}{$M S X 1$} & $\mathrm{~F}$ & CTCCGCAAACACAAGACGAAC & NM_002448 & 391 & [23] \\
\hline & $\mathrm{R}$ & CACATGGGCCGTGTAGAGTC & & & \\
\hline \multirow[t]{2}{*}{ Hes1 } & $\mathrm{F}$ & TCAACACGACACCGGATAAAC & NM_005524 & 153 & $325652058 c 1$ \\
\hline & $\mathrm{R}$ & GCCGCGAGCTATCTTTCTTCA & & & \\
\hline \multirow[t]{2}{*}{ GAPDH } & $\mathrm{F}$ & AGCAATGCCTCCTGCACCACCAAC & NM_002046 & 137 & [23] \\
\hline & $\mathrm{R}$ & CCGGAGGGGCCATCCACAGTCT & & & \\
\hline \multirow[t]{2}{*}{$R U N X 2$} & $\mathrm{~F}$ & AGGCGGTCAGAGAACAAAC & NM_001015051 & 129 & Hs.PT.56a.19568141 \\
\hline & $\mathrm{R}$ & СТTСАСАААТССТССССААGТ & & & \\
\hline \multirow[t]{2}{*}{$S P 7$} & $\mathrm{~F}$ & GGAGCCATAGTGAACTTCCTC & NM_152860 & 94 & Hs.PT.58.3437800 \\
\hline & $\mathrm{R}$ & АGСTСТСТССАTСTGСCT & & & \\
\hline \multirow[t]{2}{*}{ PPARG } & $\mathrm{F}$ & GGATTCAGCTGGTCGATATCAC & NM_138711 & 120 & Hs.PT.58.25464465 \\
\hline & $\mathrm{R}$ & GTTTCAGAAATGCCTTGCAGT & & & \\
\hline$L P L$ & $\mathrm{~F}$ & CCTTGGAACTGCACCTGTAG & NM_000237 & 148 & Hs.PT.58.45792913 \\
\hline
\end{tabular}

Abbreviations: NES, Nestin; SNAI1, Snail Family Transcriptional Repressor 1; SANI2, Snail Family Transcriptional Repressor 2; MSX1, Msh Homeobox 1; GAPDH, Glyceraldehyde-3-Phosphate Dehydrogenase; RUNX2, RUNX Family Transcription Factor 2; PPARG, Peroxisome Proliferator Activated Receptor Gamma; LPL, Lipoprotein Lipase; CHAD, Chondroadherin; Col2A1, Collagen Type II Alpha 1; ACTA2, Actin Alpha 2; TUBB3, Tubulin Beta 3; NCAM, Neural Cell Adhesion Molecule 1; LRRC17, Leucine Rich Repeat Containing 17; KCNK12, Potassium Two Pore Domain Channel Subfamily K Member 12; HAPLN1, Hyaluronan And Proteoglycan Link Protein 1; SUSD2, Sushi Domain Containing 2; PTPRE, Protein Tyrosine Phosphatase Receptor Type E; FBLN2, Fibulin 2; DLL1, Delta Like Canonical Notch Ligand 1; ACTB, Actin Beta. 


\begin{tabular}{|c|c|c|c|c|c|}
\hline \multicolumn{2}{|l|}{ Gene } & Primer/Probe sequence ( $5^{\prime}$ to $\left.3^{\prime}\right)$ & GenBank & $\begin{array}{l}\text { Size } \\
\text { (bp) }\end{array}$ & \multirow[t]{2}{*}{$\begin{array}{l}\text { Reference } \\
\text { Primer bank } \\
\text { ID/Assay name }\end{array}$} \\
\hline & $\mathrm{R}$ & GAGAAGCTATCCGCGTGA & & & \\
\hline \multirow[t]{2}{*}{$C H A D$} & $\mathrm{~F}$ & TGTTTCAGCGTGGTTACAC & NM_001267 & 109 & Hs.PT.58.40907038 \\
\hline & $\mathrm{R}$ & ACAATGCCTTCCAGTCCTTT & & & \\
\hline \multirow[t]{2}{*}{ Col2A1 } & $\mathrm{F}$ & GTTTTCCAGCTTCACCATCATC & NM_033150 & 121 & Hs.PT.58.4107778 \\
\hline & $\mathrm{R}$ & СCTCAAGGATTTCAAGGCAAT & & & \\
\hline \multirow[t]{2}{*}{ ACTA2 } & $\mathrm{F}$ & CACGAAGCTCATTGTAGAAAGAG & NM_001141945 & 115 & Hs.PT.56a.39662523 \\
\hline & $\mathrm{R}$ & GCACAGAGCAAAAGAGGAATC & & & \\
\hline \multirow[t]{2}{*}{ TUBB3 } & $\mathrm{F}$ & CCTCCGTGTAGTGACCCTT & NM_001197181 & 89 & Hs.PT.58.20385221 \\
\hline & $\mathrm{R}$ & GGCCTTTGGACATCTCTTCAG & & & \\
\hline \multirow[t]{2}{*}{ CD24 } & $\mathrm{F}$ & САATGTCAAATCCAAAGCCTCA & NM_013230 & 130 & Hs.PT.58.45758278.g \\
\hline & $\mathrm{R}$ & CTCAACGTATTGTTTCGACAGC & & & \\
\hline \multirow{2}{*}{$\begin{array}{l}\text { CD56 } \\
\text { (NCAM1) }\end{array}$} & $\mathrm{F}$ & CCGTCATCCTGCTTGATCAG & NM_181351 & 110 & Hs.PT.58.3970990 \\
\hline & $\mathrm{R}$ & GAGTTCAAGACGCAGCCA & & & \\
\hline \multirow[t]{2}{*}{$L R R C 17$} & $\mathrm{~F}$ & CAAGTCTTCTAATACGCCATAGTCA & NM_005824 & 136 & Hs.PT.58.615298 \\
\hline & $\mathrm{R}$ & TGAGATGAAACCCTGCAAGTAG & & & \\
\hline \multirow[t]{2}{*}{ KCNK12 } & $\mathrm{F}$ & AGGTTGAAGAACAGGATGGTC & NM_022055 & 130 & Hs.PT.58.21235707 \\
\hline & $\mathrm{R}$ & TACTTCGTGGGCACCGT & & & \\
\hline \multirow[t]{2}{*}{ HAPLN1 } & $\mathrm{F}$ & CAGATTGAAATCAGCACCAGAAG & NM_001884 & 143 & Hs.PT.58.3994973 \\
\hline & $\mathrm{R}$ & CGCTAGCTTCACTTGATCTCC & & & \\
\hline \multirow[t]{2}{*}{ SUSD2 } & $\mathrm{F}$ & GCATGATGGAGACCCTGTC & NM_019601 & 89 & Hs.PT.58.1294267 \\
\hline & $\mathrm{R}$ & GGAGGTGCTGAGCTTCAC & & & \\
\hline PTPRE & $\mathrm{F}$ & СTCCCAGACCATTCTCCAGA & NM_130435 & 103 & Hs.PT.58.40307003 \\
\hline \multicolumn{6}{|c|}{$\begin{array}{l}\text { Abbreviations: NES, Nestin; SNAI1, Snail Family Transcriptional Repressor 1; SANI2, Snail Family } \\
\text { Transcriptional Repressor 2; MSX1, Msh Homeobox 1; GAPDH, Glyceraldehyde-3-Phosphate } \\
\text { Dehydrogenase; RUNX2, RUNX Family Transcription Factor 2; PPARG, Peroxisome Proliferator Activated } \\
\text { Receptor Gamma; LPL, Lipoprotein Lipase; CHAD, Chondroadherin; Col2A1, Collagen Type II Alpha 1; } \\
\text { ACTA2, Actin Alpha 2; TUBB3, Tubulin Beta 3; NCAM, Neural Cell Adhesion Molecule 1; LRRC17, Leucine } \\
\text { Rich Repeat Containing 17; KCNK12, Potassium Two Pore Domain Channel Subfamily K Member 12; } \\
\text { HAPLN1, Hyaluronan And Proteoglycan Link Protein 1; SUSD2, Sushi Domain Containing 2; PTPRE, } \\
\text { Protein Tyrosine Phosphatase Receptor Type E; FBLN2, Fibulin 2; DLL1, Delta Like Canonical Notch } \\
\text { Ligand 1; ACTB, Actin Beta. }\end{array}$} \\
\hline
\end{tabular}




\begin{tabular}{|c|c|c|c|c|c|}
\hline \multirow[t]{2}{*}{ Gene } & & Primer/Probe sequence ( $5^{\prime}$ to $\left.3^{\prime}\right)$ & GenBank & $\begin{array}{l}\text { Size } \\
\text { (bp) }\end{array}$ & $\begin{array}{l}\text { Reference } \\
\text { Primer bank } \\
\text { ID/Assay name }\end{array}$ \\
\hline & $\mathrm{R}$ & $\begin{array}{l}\text { CAATGCTTCCTACATAGATGGTTA } \\
\text { C }\end{array}$ & & & \\
\hline \multirow[t]{2}{*}{ FBLN2 } & $\mathrm{F}$ & CCAGGCACTCGTCATTGTC & NM_001998 & 115 & Hs.PT.58.38361266 \\
\hline & $\mathrm{R}$ & ССААСТСТGТССАТТСТАТССС & & & \\
\hline \multirow[t]{2}{*}{ DLL 1} & $\mathrm{~F}$ & GTCACAAAATCCATGCTGCTC & NM_005618 & 96 & Hs.PT.58.41063402 \\
\hline & $\mathrm{R}$ & GTGGGGAGAAAGTGTGCAA & & & \\
\hline \multirow[t]{2}{*}{ ACTB } & $\mathrm{F}$ & CCTTGCACATGCCGGAG & NM_001101 & 110 & Hs.PT.39a.22214847 \\
\hline & $\mathrm{R}$ & ACAGAGCCTCGCCTTTG & & & \\
\hline \multicolumn{6}{|c|}{$\begin{array}{l}\text { Abbreviations: NES, Nestin; SNAI1, Snail Family Transcriptional Repressor 1; SANI2, Snail Family } \\
\text { Transcriptional Repressor 2; MSX1, Msh Homeobox 1; GAPDH, Glyceraldehyde-3-Phosphate } \\
\text { Dehydrogenase; RUNX2, RUNX Family Transcription Factor 2; PPARG, Peroxisome Proliferator Activated } \\
\text { Receptor Gamma; LPL, Lipoprotein Lipase; CHAD, Chondroadherin; Col2A1, Collagen Type II Alpha 1; } \\
\text { ACTA2, Actin Alpha 2; TUBB3, Tubulin Beta 3; NCAM, Neural Cell Adhesion Molecule 1; LRRC17, Leucine } \\
\text { Rich Repeat Containing 17; KCNK12, Potassium Two Pore Domain Channel Subfamily K Member 12; } \\
\text { HAPLN1, Hyaluronan And Proteoglycan Link Protein 1; SUSD2, Sushi Domain Containing 2; PTPRE, } \\
\text { Protein Tyrosine Phosphatase Receptor Type E; FBLN2, Fibulin 2; DLL1, Delta Like Canonical Notch } \\
\text { Ligand 1; ACTB, Actin Beta. }\end{array}$} \\
\hline
\end{tabular}

\section{Figures}



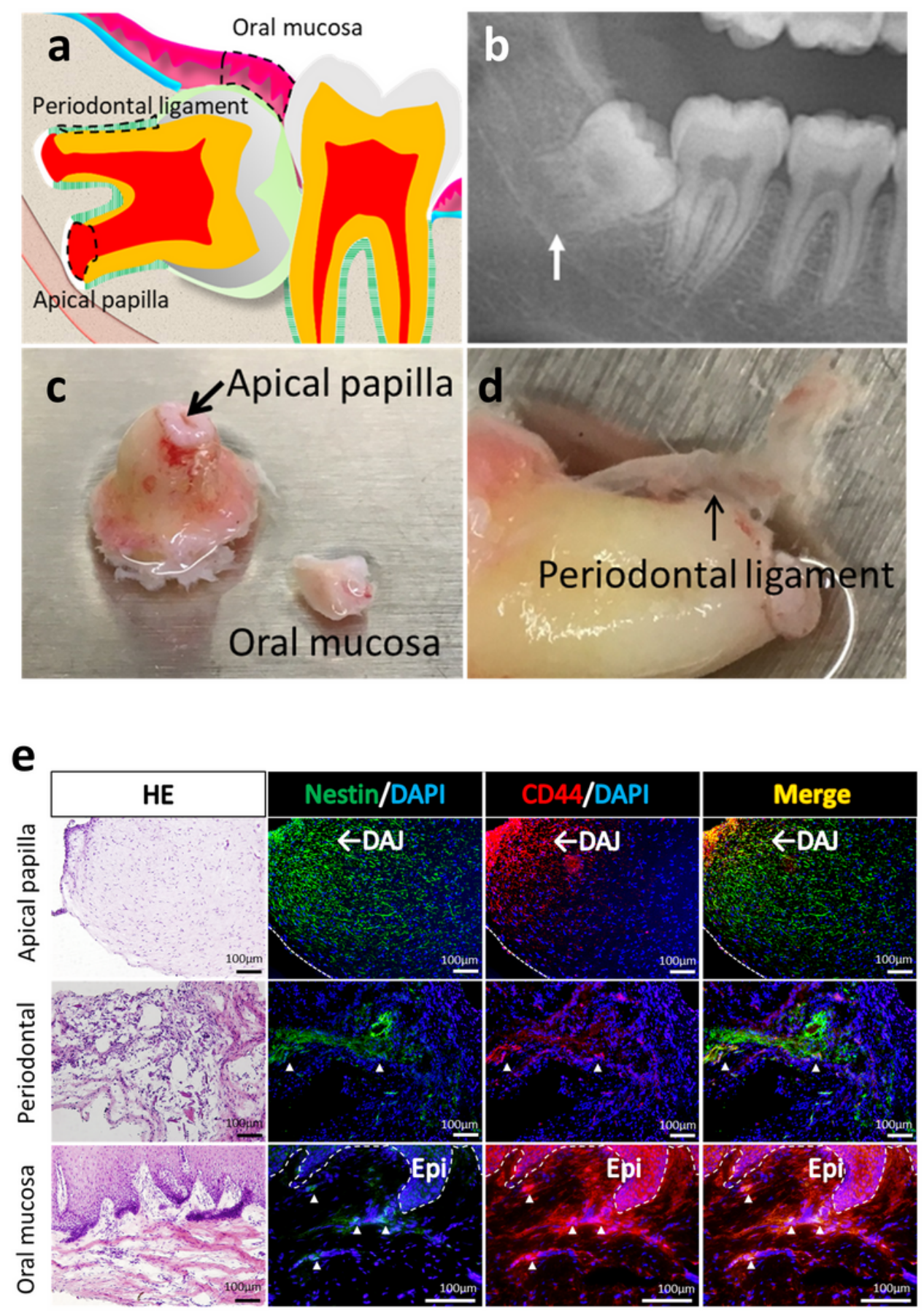

\section{Figure 1}

Characterization of human apical papilla, periodontal ligament, and oral mucosal tissue. (a) Schema showing impacted developing third molar. (b) Panoramic XP of the human impacted third molar with immature root apex. (c, d) Photographs of human apical papilla (AP) (c), periodontal ligament (PDL) (d), and oral mucosa (OM) (c) tissue. (e) H\&E staining, and immunohistochemical analysis of human AP, PDL, and OM tissues. Abbreviations: DAPI, 4',6-diamidino-2-phenylindole; DAJ, dentin-apical pulp junction; Epi, epithelium; HE, Hematoxylin-eosin staining. 


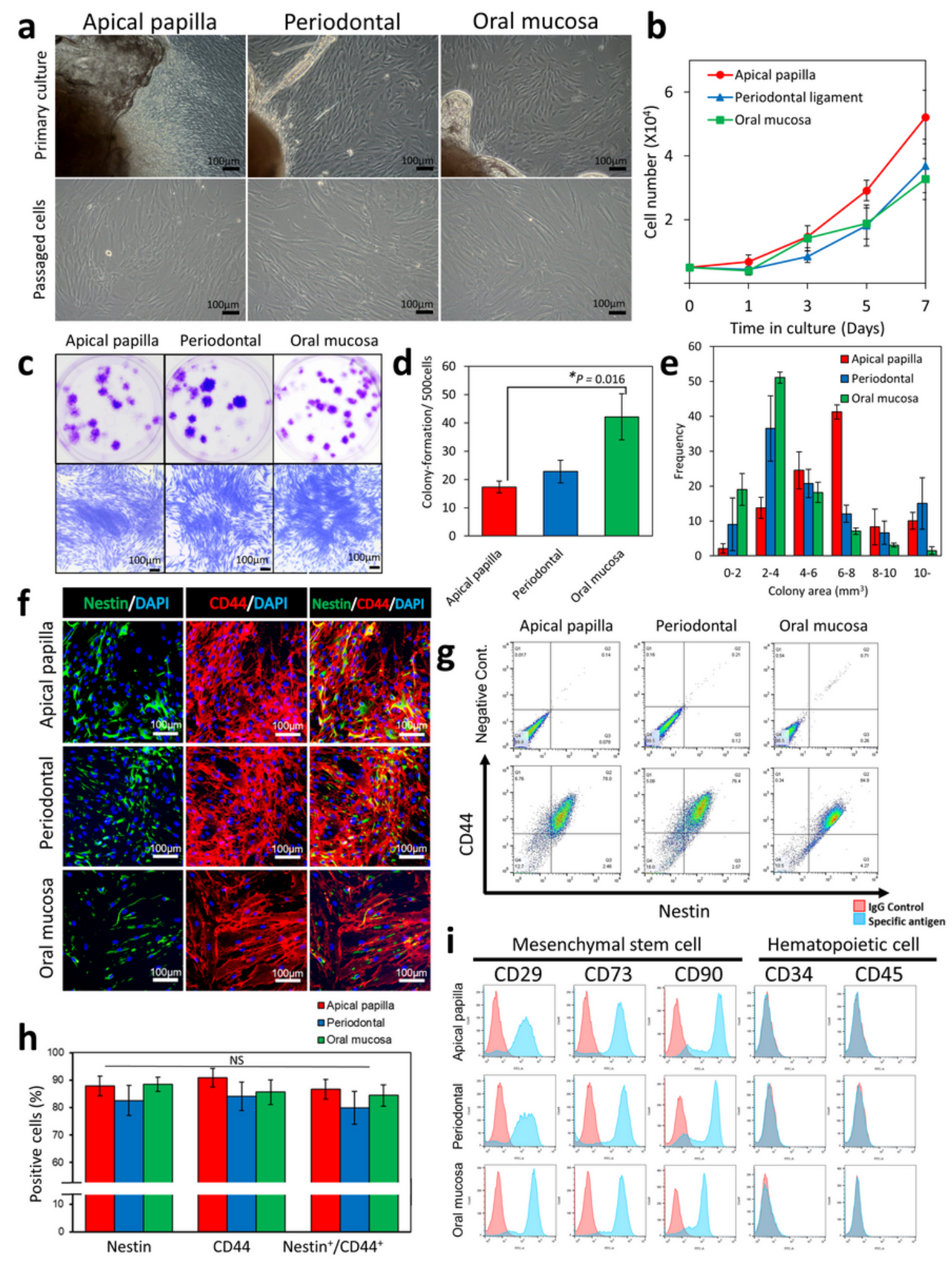

Figure 2

Characterization of human APDCs, PDLDCs, and OMSDCs. (a) Morphology of cultured APDCs, PDLDCs, and OMSDCs in vitro. Upper panel: primary cultured cells around the explanted tissue; lower panel: exponential growth of passaged cells in monolayer culture. (b) Cell growth curves of APDCs, PDLDCs, and OMSDCS ( $n=$ 5, patient-matched). (c) Photographs of colony-forming unit fibroblasts from APDCs, PDLDCs, and OMSDCs at 14 days. (d) Colony-formation assays for APDCs, PDLDCs, and OMSDCs ( $n=5$, patient-matched).

Colonies stained with crystal violet. (e) Measurement of colony areas of APDCs, PDLDCs, and OMSDCs ( $\mathrm{n}=$ 
4, patient-matched). (f) Immunohistochemistry for nestin and CD44. (g) Flow cytometry analysis of the expression of nestin and CD44. $(\mathrm{h})$ The percentage expression of nestin, CD44, and nestin/CD44 in cells $(\mathrm{n}=$ 3, patient-matched). (i) Expression of surface markers of APDCs, PDLDCs, and OMSDCs. Average data are expressed as mean \pm standard error (SE). Abbreviations: DAPI, 4',6-diamidino-2-phenylindole. ${ }^{*} \mathrm{P}<0.05$.

a

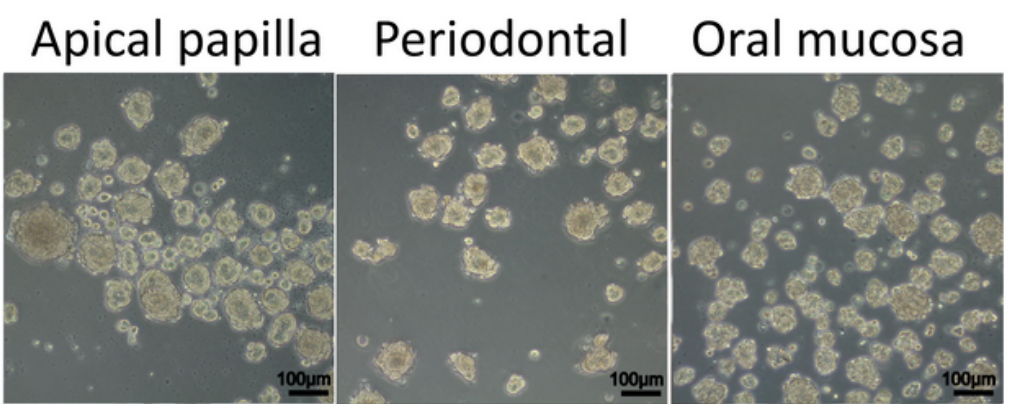

b

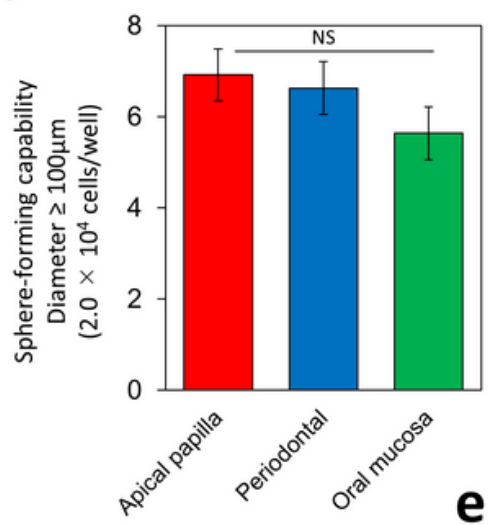

C

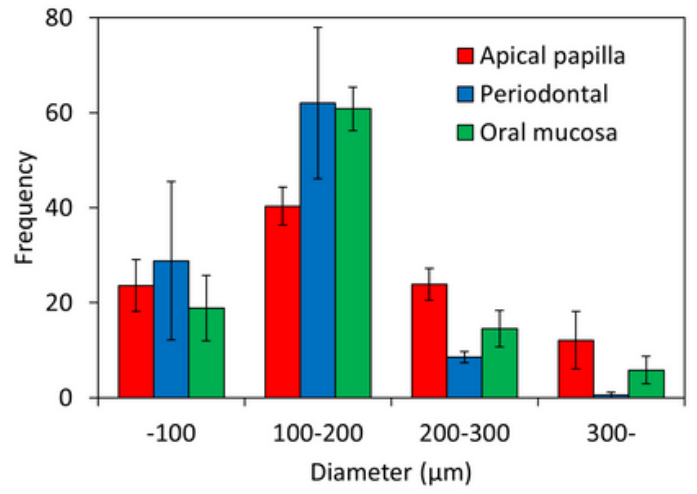

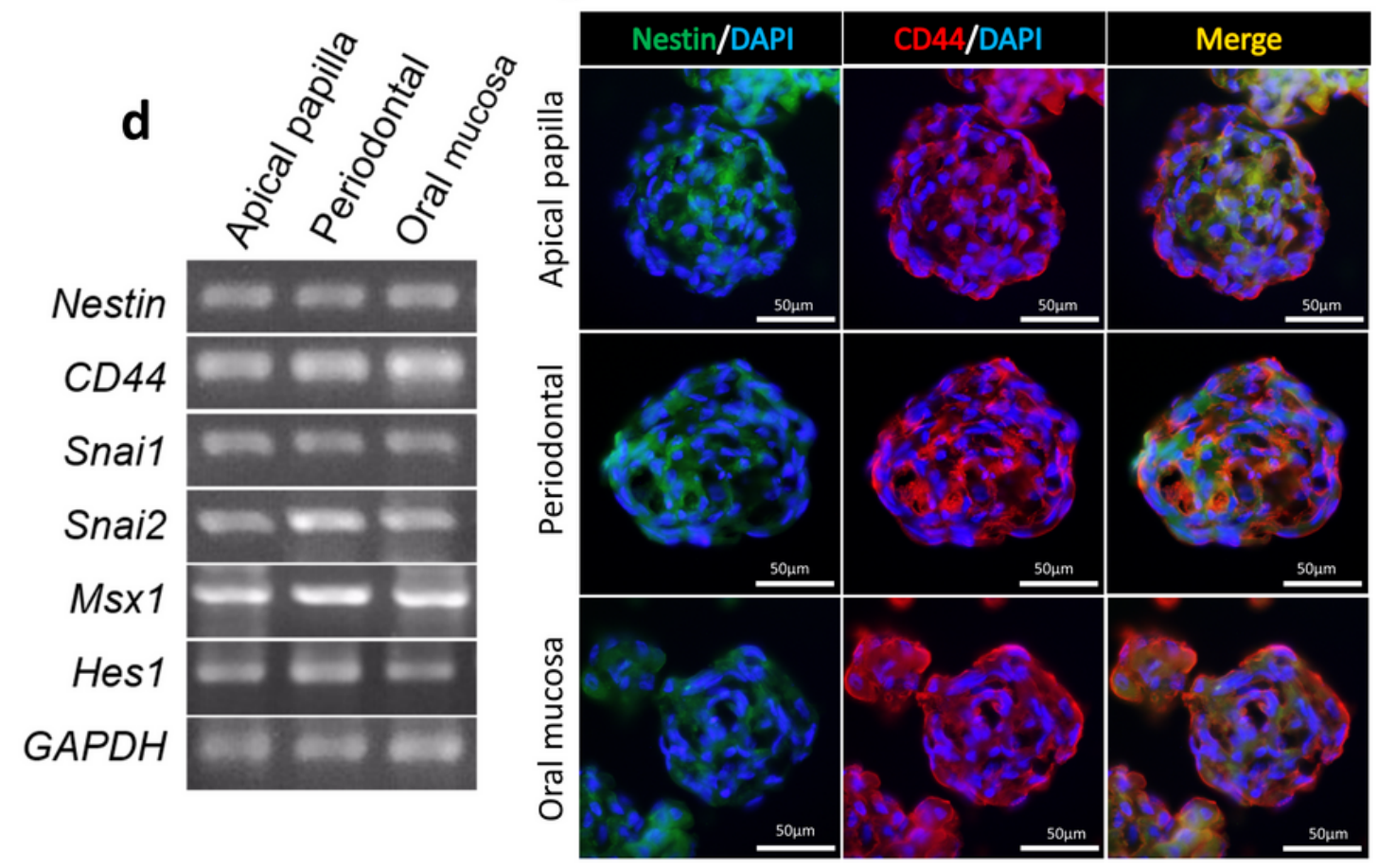

Figure 3

Isolation and characterization of sphere-forming APDCs, PDLDCs, and OMSDCs. (a) APDCs, PDLDCs, and OMSDCs formed spheres $(5.0 \times 104$ cells/well). (b) Sphere-forming abilities $(n=6$, patient-matched). 
Spheres with diameter $\geq 100 \mu \mathrm{m}$ were counted after 7 days of sphere culture $(2.0 \times 104$ cells/well, $n=6$, patient-matched). (c) Measurement of the diameter of spheres ( $n=3$, patient-matched). (d) Semiquantitative RT-PCR analysis of NES, CD44, SNAI1, SNAI2, MSX1, and HES1 mRNAs. GAPDH was used as the internal control. (e) Immunohistochemical analysis of nestin and CD44. Results are expressed as mean \pm SE. Abbreviations: DAPI, 4',6-diamidino-2-phenylindole.
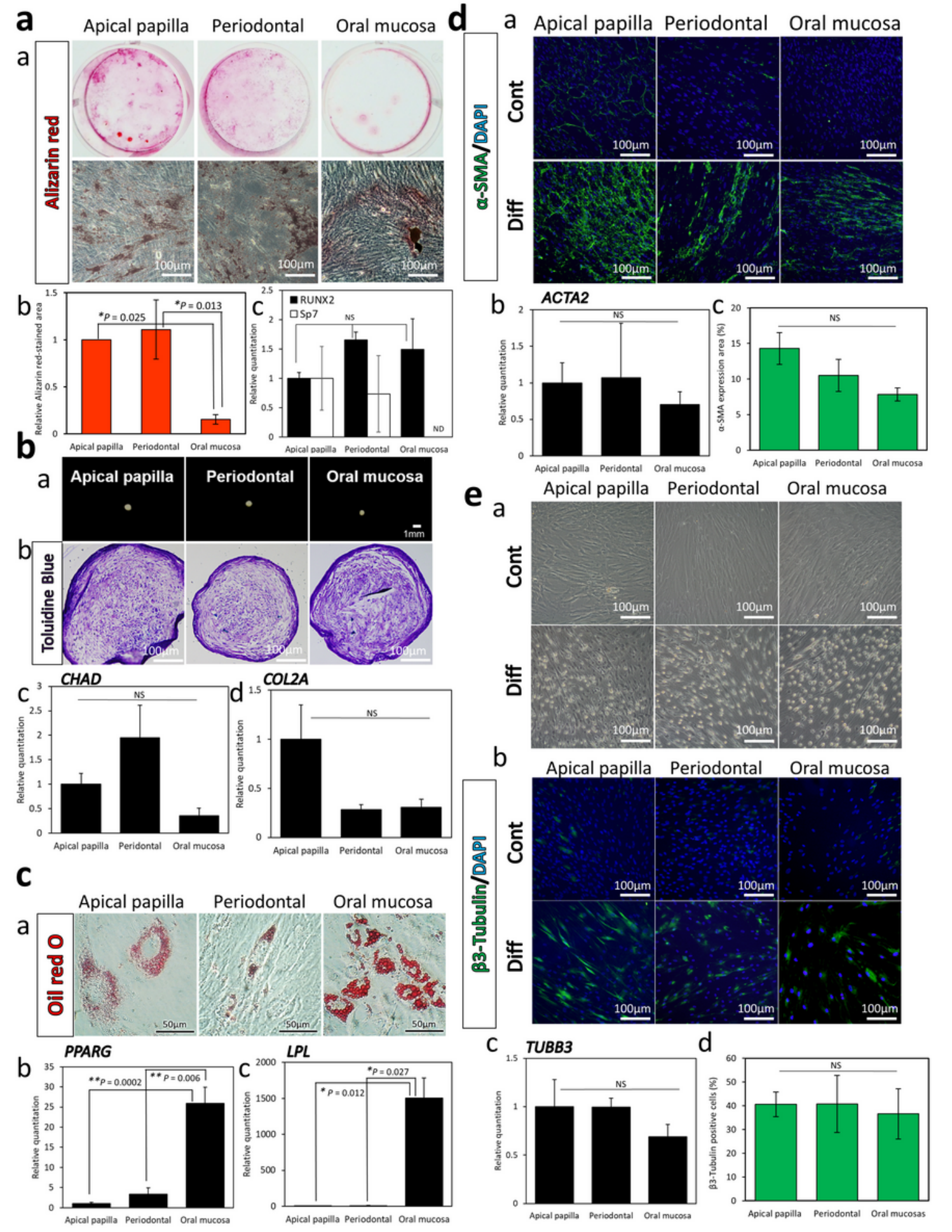

Figure 4 
Differentiation capacity of sphere-forming APDCs, PDLDCs, and OMSDCs to neural crest lineage cells. Identification of differentiation using (a) Alizarin Red S staining for mineralized cells, (b) toluidine blue staining for chondrocytes, (c) Oil Red $\mathrm{O}$ staining for adipocytes, (d) a-SMA immunostaining for myocytes, and (e) $\beta 3$-tubulin immunostaining for neurons. (a[a]) Images of Alizarin Red-stained differentiated cells (patient-matched). (a[b]) The relative Alizarin Red-stained area following culture under mineralized-cell differentiation conditions for 3 weeks. (a[c]) Quantitative RT-PCR analysis of RUNX2 and SP7 ( $n=4$, patientmatched). (b[a]) Photographs of micromass pellets cultured under a chondrogenic condition for 3 weeks after staining with toluidine blue. (b[b]) Quantitative RT-PCR analysis of CHAD (b[c]) and COL2A $(b[d])(n=3$, patient-matched). (c[a]) Microscopic images of Oil Red O-stained adipocytes (patient-matched) after culture under adipogenic conditions for 3 weeks. (c[b, c]) Quantitative RT-PCR analysis of PPARG (c[b]) and LPL $(c[c])(n=4$, patient-matched). (d[a]) Microscopic images showing a-SMA staining after culture in conditioned or myogenic differentiation medium for 7 days. (d[b]) Quantitative RT-PCR analysis of ACTA2 ( $n$ $=4$, patient-matched). (d[c]) Immunohistochemical analysis of a-SMA $(n=3$, patient-matched). (e[a]) Microscopic images after culture in conditioned or neural cell differentiation medium for 7 days. (e[b]) Immunohistochemical analysis of $\beta 3$-tubulin ( $n=3$, patient-matched). (e[c]) Quantitative RT-PCR analysis of TUBB3 ( $n=4$, patient-matched). (e[d]) Immunohistochemical analysis of $\beta 3$-tubulin $(n=3$, patient-matched). Average data are expressed as mean \pm SE. Abbreviations: Cont., control group; DAPI, 4',6-diamidino-2phenylindole; Diff., differentiation group. ${ }^{\star} \mathrm{P}<0.05,{ }^{*} \mathrm{P}<0.01$. 


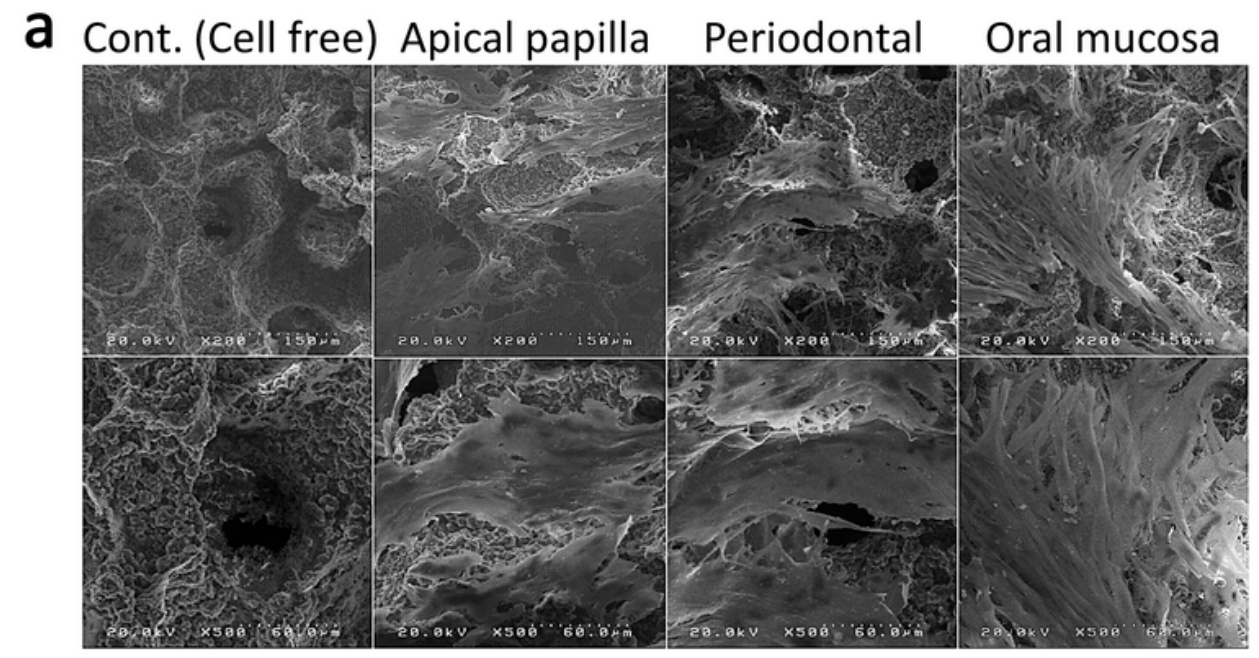

b

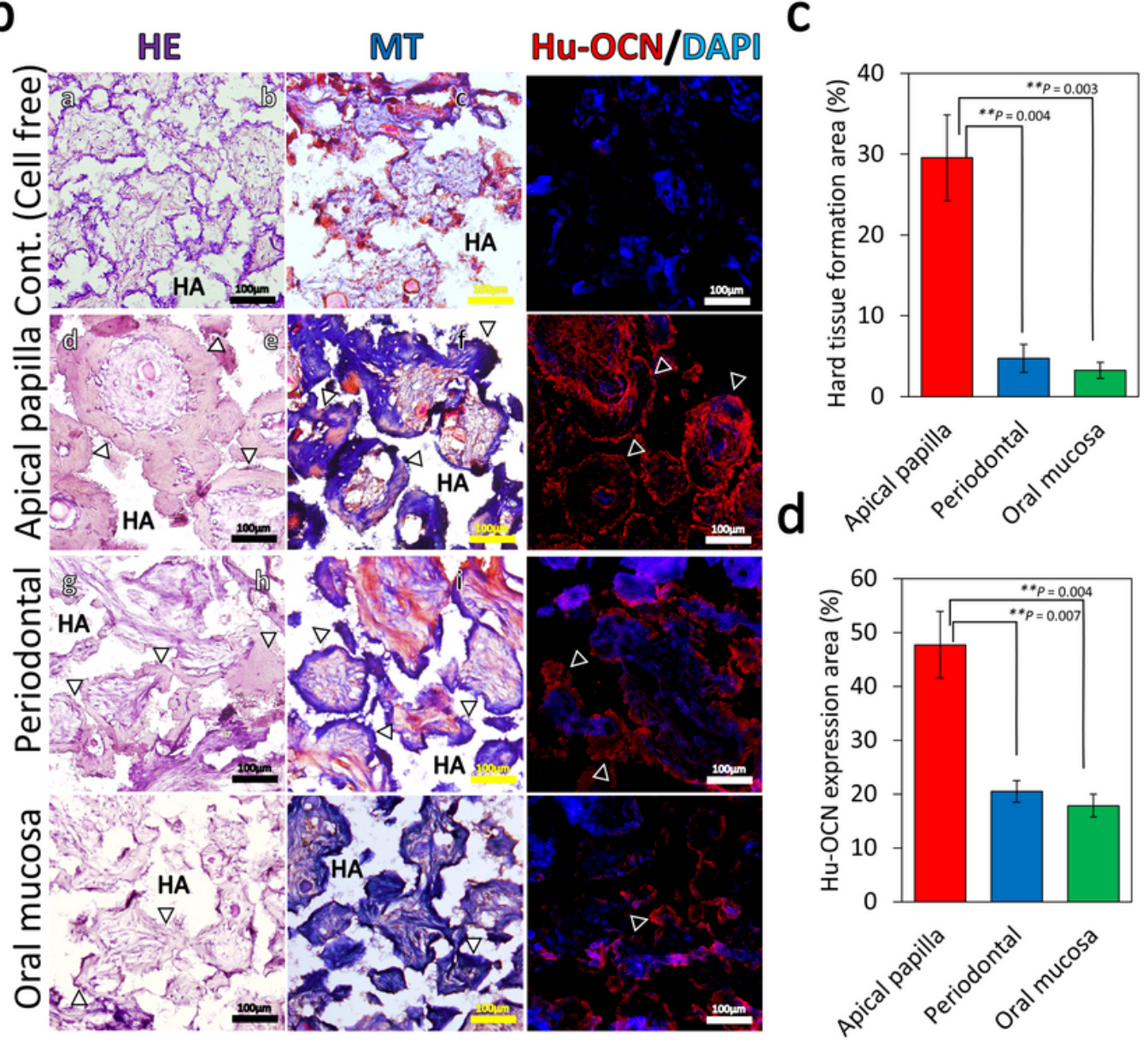

\section{Figure 5}

In vivo hard tissue-forming ability of APDCs, PDLDCS, and OMSDCs. (a) SEM images of cells adhered to porous hydroxyapatite scaffolds. (b) H\&E staining, Masson's trichrome staining, and immunohistochemical analysis of transplanted tissues. H\&E staining revealed hard tissue regeneration in vivo. Masson's trichrome staining revealed that regenerated hard tissues were composed of collagen fibers. Immunofluorescence staining was performed for human osteocalcin. (c) Quantitative analysis of the area with hard tissue formation ( $n=3$, patient-matched). (d) Quantitative analysis of human osteocalcin area $(n=3$, patient- 
matched). Average data are expressed as mean \pm SE. Abbreviations: Cont., control group; DAPI, 4',6diamidino-2-phenylindole; HA, hydroxyapatite; HE, hematoxylin-eosin staining; Hu-OCN, human osteocalcin; MT, Masson's trichrome staining. Arrowhead: hard tissue. ${ }^{* *} \mathrm{P}<0.01$.

a

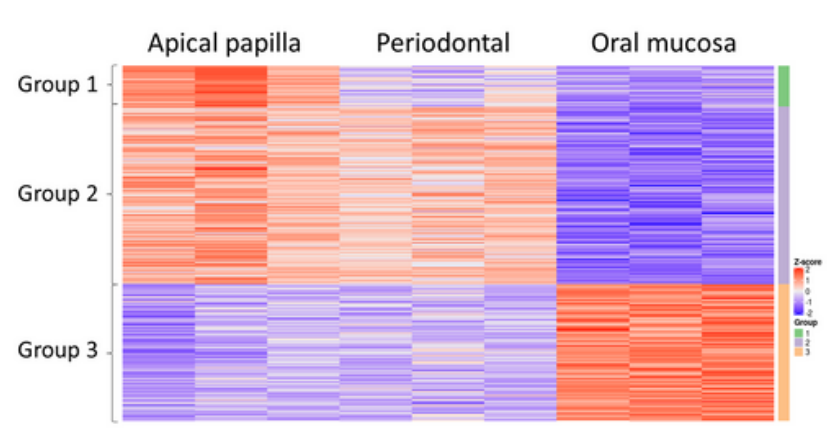

b

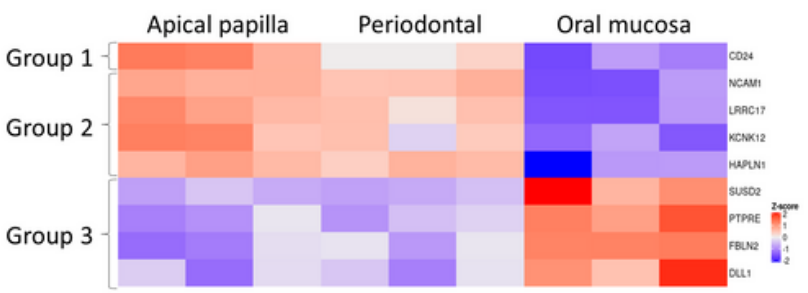

d
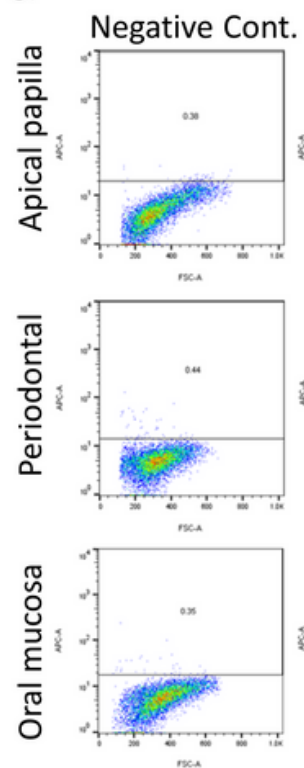

C

CD56 (NCAM1)
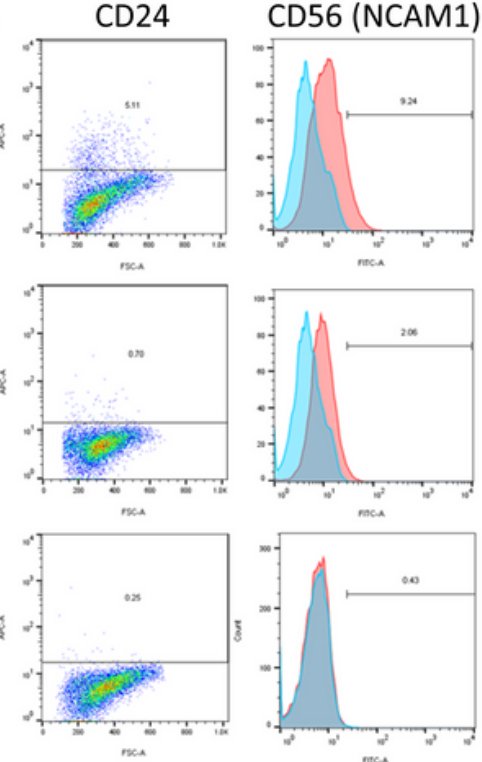

$\square$ IgG control

CD56(NCAM1)

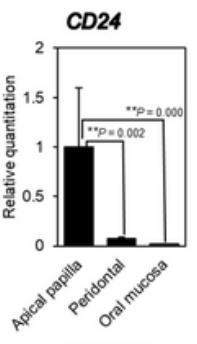

KCNK12
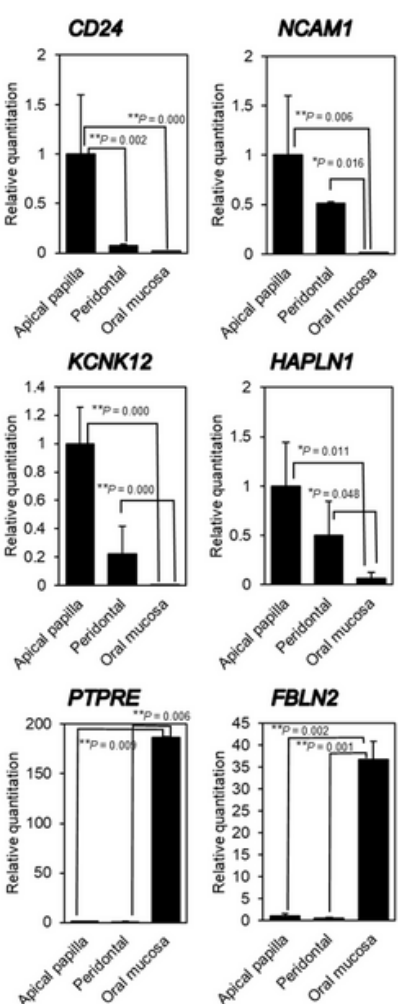

HAPLN1
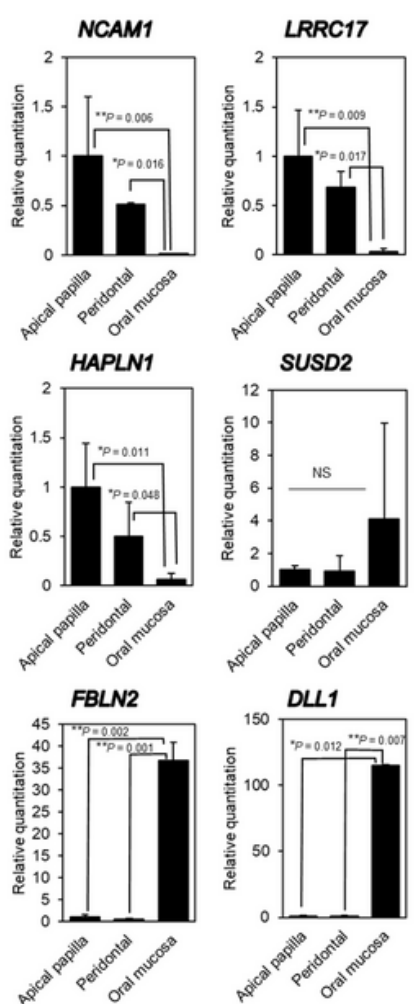

SUSD2
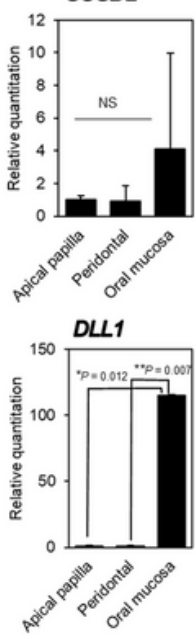

e

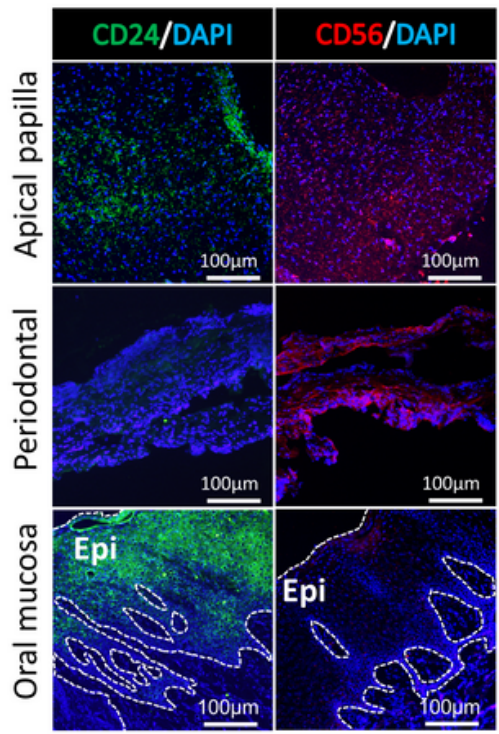

Figure 6

Differences in transcriptome and expression of cell surface proteins among sphere-forming APDCs, PDLDCs, and OMSDCs. (a) Heatmap of significant differences in the transcriptome and expression among sphereforming APDCs, PDLDCs, and OMSDCs. Cutoff line: Fold change $>2.0$ and adjusted $P<0.05$. (b) Common 
differentially expressed genes identified using microarray analysis. (c) Quantitative RT-PCR analysis showing differences in the expression levels of genes selected using microarray analysis in APDCs, PDLDCs, and OMSDCs. (d) Flow cytometric analyses of differentially expressed CD24 and CD56 (NCAM1). (e) Immunohistochemical analyses of differentially expressed CD24 and CD56 (NCAM1) in human oral tissues. Abbreviations: DAPI, 4',6-diamidino-2-phenylindole. ${ }^{*} \mathrm{P}<0.05,{ }^{*} \mathrm{P}<0.01$.

\section{Supplementary Files}

This is a list of supplementary files associated with this preprint. Click to download.

- SupplementalTable1.docx

- renamed175c6.tif 